\title{
Health and Mortality Delta: Assessing the Welfare Cost of Household Insurance Choice*
}

\author{
Ralph S. J. Koijen ${ }^{\dagger} \quad$ Stijn Van Nieuwerburgh ${ }^{\ddagger}$ Motohiro Yogo ${ }^{\S}$
}

November 25, 2011

\begin{abstract}
We develop a pair of risk measures for the universe of health and longevity products that includes life insurance, annuities, and supplementary health insurance. Health delta measures the differential payoff that a policy delivers in poor health, while mortality delta measures the differential payoff that a policy delivers at death. Optimal portfolio choice simplifies to the problem of choosing a combination of health and longevity products that replicates the optimal exposure to health and mortality delta. For each household in the Health and Retirement Study, we calculate the health and mortality delta implied by its ownership of life insurance, annuities including private pensions, supplementary health insurance, and long-term care insurance. For the median household aged 51 to 58 , the lifetime welfare cost of market incompleteness and suboptimal portfolio choice is 28 percent of total wealth.
\end{abstract}

JEL classification: D14, D91, G11, G22, I10

Keywords: Annuity, Health insurance, Life insurance, Medical expenditure

\footnotetext{
${ }^{\dagger}$ University of Chicago, NBER, and Netspar-Tilburg University (e-mail: ralph.koijen@chicagobooth.edu)

${ }^{\ddagger}$ New York University, NBER, and CEPR (e-mail: svnieuwe@stern.nyu.edu)

${ }^{\S}$ Federal Reserve Bank of Minneapolis (e-mail: yogo@minneapolisfed.org)
} 


\section{Introduction}

Retail financial advisors and insurance companies offer a wide variety of health and longevity products including life insurance, annuities, supplementary health insurance, and long-term care insurance. Each of these products comes in a potentially confusing variety of maturities and payout structures. Consider, for example, a simplified menu of life insurance and annuity products offered by TIAA-CREF in Table 1. This variety of products begs for a risk measure that allows households to assess to what extent these products are complements or substitutes and to choose an optimal portfolio of products. Such risk measures already exist in other parts of the retail financial industry. For example, beta measures the exposure of an equity product to aggregate market risk, and duration measures the exposure of a fixed-income product to interest-rate risk. The existence of such risk measures, based on sound economic theory, has proven to be tremendously valuable in quantifying and managing financial risk for both households and institutions alike.

This paper develops a pair of risk measures for health and longevity products, which we refer to as health and mortality delta. Health delta measures the differential payoff that a policy delivers in poor health, while mortality delta measures the differential payoff that a policy delivers at death. Each household has an optimal exposure to health and mortality delta that depends on preferences (e.g., risk aversion and bequest motive) and characteristics (e.g., birth cohort, age, health, and wealth). Optimal portfolio choice simplifies to the problem of choosing a combination of health and longevity products, not necessarily unique,

${ }^{*}$ For comments and discussions, we thank Jiajia Cui, Frank de Jong, Liran Einav, Michael Gallmeyer, Ben Heijdra, Robin Lumsdaine, Theo Nijman, Sam Schulhofer-Wohl, and seminar participants at APG, Australian National University, Columbia University, Erasmus University, Federal Reserve Bank of Minneapolis, Financial Engines, Georgetown University, Georgia State University, Maastricht University, New York University, Tilburg University, University of Minnesota, University of New South Wales, University of Technology Sydney, University of Tokyo, University of Utah, Vanderbilt University, the 2011 Netspar International Pension Workshop, the 2011 SED Annual Meeting, the 2011 UBC Summer Finance Conference, and the 2011 Conference on Economic Decisionmaking. This paper is based upon work supported under a Netspar research grant. The Health and Retirement Study is sponsored by the National Institute of Aging (grant U01-AG009740) and is conducted by the University of Michigan. The views expressed herein are those of the authors and not necessarily those of the Federal Reserve Bank of Minneapolis, the Federal Reserve System, or the National Bureau of Economic Research. 
that replicates the optimal health and mortality delta.

We apply our theory of optimal portfolio choice to assess the actual choices that households make in regard to health and longevity products. Figure 1 reports the ownership rates for term- and whole-life insurance, annuities including private pensions, supplementary health insurance, and long-term care insurance in the Health and Retirement Study. The ownership rate for term-life insurance exceeds 60 percent for individuals aged 51 to 58 , while the ownership rate for annuities including private pensions exceeds 50 percent for individuals aged 67 to 74 . In comparison, the ownership rates for supplementary health insurance and long-term care insurance are much lower. For example, the ownership rate for long-term care insurance is only slightly above 10 percent for individuals aged 67 to 74 . How close are these observed choices to achieving the optimal private demand for health and longevity products, given the public provision of insurance through Social Security and Medicare?

To answer this question, we calculate health and mortality delta for each household, implied by its ownership of health and longevity products. We then calculate the welfare cost for each household as a function of deviations of the observed health and mortality delta from the optimal health and mortality delta. For the median household aged 51 to 58 , the lifetime welfare cost is 28 percent of total wealth, which includes the present value of future income in excess of out-of-pocket health expenses. We interpret this welfare cost as the joint cost of market incompleteness and suboptimal portfolio choice. Most of the welfare cost is explained by deviations of the observed mortality delta from the optimal mortality delta, rather than by deviations of the observed health delta from the optimal health delta. In other words, choices over life insurance and annuities have a much larger impact on the welfare cost than do choices over supplementary health insurance and long-term care insurance.

Another way to cast our findings is that there is significant variation, especially in mortality delta, that remains unexplained by life-cycle effects or observed household characteristics that capture potential heterogeneity in bequest motives or private information about health. We highlight a new puzzle that is distinct from the so-called annuity puzzle: the hetero- 
geneity in degrees of annuitization conditional on household characteristics, rather than the average level of annuitization, is puzzling from the perspective of our model. Our work is not the first attempt to explain household demand for health and longevity products such as life insurance (Bernheim, 1991; Inkmann and Michaelides, 2011) and annuities (Brown, 2001; Inkmann, Lopes, and Michaelides, 2011). However, a key methodological contribution is to collapse household insurance choice into a pair of sufficient statistics, health and mortality delta, which explicitly account for the complementarity of life insurance and annuities as well as the substitutability of long-term life insurance and supplementary health insurance.

The remainder of the paper is organized as follows. In Section 2, we develop a life-cycle model in which a household faces health and mortality risk and invests in life insurance, annuities, and supplementary health insurance. In Section 3, we derive the solution to the life-cycle problem under complete markets as well as a key formula for measuring the welfare cost of deviations from the optimal insurance of health and mortality risk. In Section 4, we calibrate the life-cycle model using the Health and Retirement Study. In Section 5, we estimate the welfare cost of market incompleteness and suboptimal portfolio choice. In Section 6, we illustrate how a household can replicate the optimal health and mortality delta through existing health and longevity products. Section 7 concludes. The appendices contain proofs and details about the data that are omitted in the main text.

\section{A Life-Cycle Model with Health and Mortality Risk}

In this section, we develop a life-cycle model in which a household faces health and mortality risk that affects life expectancy, health expenses, and the marginal utility of consumption or wealth. The household can invest in life insurance, annuities, supplementary health insurance, and a bond. The household may face borrowing or portfolio constraints, which may prevent it from achieving the optimal insurance of health and mortality risk. 


\subsection{Health and Mortality Risk}

In our model, health refers to any information that is verifiable through medical underwriting that involves a health examination and a review of medical history. For tractability, we do not model residual private information, such as self assessments of health, that might affect the demand for health and longevity products. In Section 5, however, we examine private information as a potential explanation for the heterogeneity in the demand for health and longevity products.

\subsubsection{Health Transition Probabilities}

The household lives for at most $T$ periods and dies with certainty in period $T+1$. In each period $t \in[1, T]$, the household's health is in one of three states, indexed as $h_{t} \in\{1,2,3\} .{ }^{1}$ The health states are ordered so that $h_{t}=1$ corresponds to death, $h_{t}=2$ corresponds to poor health, and $h_{t}=3$ corresponds to good health. The three-state model can be interpreted as a discrete-time analog of a continuous-time model in which a continuous process drives health risk and a jump process drives mortality risk (Milevsky and Promislow, 2001).

The household's health evolves from period $t$ to $t+1$ according to a Markov chain with a $3 \times 3$ transition matrix $\pi_{t}$. We denote the $(i, j)$ th element of the transition matrix as

$$
\pi_{t}(i, j)=\operatorname{Pr}\left(h_{t+1}=j \mid h_{t}=i\right)
$$

Conditional on being in health state $i$ in period $t, \pi_{t}(i, j)$ is the probability of being in health state $j$ in period $t+1$. Death is an absorbing state so that $\pi_{t}(1,1)=1$. Let $\mathbf{e}_{i}$ denote a $3 \times 1$ vector whose $i$ th element is one and whose other elements are zero. We define an $n$-period

\footnotetext{
${ }^{1}$ While three states is appropriate for our empirical application, it is straightforward to extend the theoretical framework to more than three states.
} 
transition probability as

$$
\pi_{t}^{n}(i, j)=\mathbf{e}_{i}^{\prime} \prod_{s=0}^{n-1} \pi_{t+s} \mathbf{e}_{j}
$$

Conditional on being in health state $i$ in period $t, \pi_{t}^{n}(i, j)$ is the probability of being in health state $j$ in period $t+n$.

We define an $n$-period mortality rate as

$$
p_{t}(n \mid i)=\left\{\begin{array}{ll}
\mathbf{e}_{i}^{\prime} \pi_{t} \mathbf{e}_{1} & \text { if } n=1 \\
\mathbf{e}_{i}^{\prime} \prod_{s=0}^{n-2} \pi_{t+s}\left[\begin{array}{lll}
\mathbf{0} & \mathbf{e}_{2} & \mathbf{e}_{3}
\end{array}\right] \pi_{t+n-1} \mathbf{e}_{1} & \text { if } n>1
\end{array} .\right.
$$

Conditional on being in health state $i$ in period $t, p_{t}(n \mid i)$ is the probability of being alive in period $t+n-1$ but dead in period $t+n$. We also define an $n$-period survival probability as

$$
q_{t}(n \mid i)=1-\pi_{t}^{n}(i, 1)
$$

Conditional on being in health state $i$ in period $t, q_{t}(n \mid i)$ is the probability of being alive in period $t+n$.

\subsubsection{Out-of-Pocket Health Expenses}

Although most households are covered by employer-provided health insurance or Medicare, they still face the risk of significant out-of-pocket health expenses, especially in old age. Many health plans only cover basic or in-network care, have capped benefits, or do not cover entire categories of health expenses. For example, Medicare does not cover nursing home care, and Medicaid only covers a limited and capped amount of nursing home care for those that qualify. Moreover, a household can lose health insurance through a layoff or a divorce. Health insurance must specify coverage for each type of future health contingency and treatment, some of which are not known to exist in advance. The fact that health 
insurance coverage can be short term or incomplete is perhaps a natural consequence of the complexity of these policies.

We model the consequences of imperfect health insurance as follows. In each period, the household faces an exogenous out-of-pocket health expense whose distribution depends on age and health. ${ }^{2}$ We denote the out-of-pocket health expense in period $t$ as $M_{t}$, or as $M_{t}\left(h_{t}\right)$ to denote its realization for a particular health state. Naturally, worse health states are associated with higher out-of-pocket health expenses. There is no health expense at death so that $M_{t}(1)=0$. Since our model is in discrete time, we account for end-of-life health expenses as incurring in the last period prior to death.

\subsection{Health and Longevity Products}

In each period $t$, the household can invest in life insurance, annuities, and supplementary health insurance of maturities one through $T-t$. In addition, the household can save in a one-period bond, which earns a gross interest rate $R$.

\subsubsection{Term-Life Insurance}

Let $1_{\left\{h_{t+s}=j\right\}}$ denote an indicator function that is equal to one if the policyholder is in health state $j$ in period $t+s$. Life insurance of term $n$ issued in period $t$ pays out a death benefit of

$$
D_{L, t+s}\left(n-s \mid h_{t+s}\right)=1_{\left\{h_{t+s}=1\right\}}
$$

upon death of the policyholder in any period $t+s \in[t+1, t+n]$. In each period $t, T-t$ is the maximum available term since the policyholder dies with certainty in period $T+1$. For our purposes, we treat whole-life insurance as a special case of term-life insurance with

\footnotetext{
${ }^{2}$ We assume that health expenses are exogenous to focus on the household's choice over a rich menu of health and longevity products. We refer to Yogo (2011) for a life-cycle model in which health expenditure is endogenous.
} 
maximum term $T-t$.

The pricing of life insurance depends on the policyholder's age and health at issuance of the policy. Naturally, younger and healthier policyholders with longer life expectancy pay a lower premium. ${ }^{3}$ Conditional on being in health state $h_{t}$ in period $t$, the price of $n$-period life insurance per unit of death benefit is

$$
P_{L, t}\left(n \mid h_{t}\right)=\sum_{s=1}^{n} \frac{p_{t}\left(s \mid h_{t}\right)}{R_{L}^{s}}
$$

where $R_{L} \leq R$ is the discount rate. The pricing of life insurance is actuarially fair when $R_{L}=R$, while $R_{L}<R$ implies that life insurance sells at a premium.

\subsubsection{Annuities}

Let $1_{\left\{h_{t+1} \neq 1\right\}}$ denote an indicator function that is equal to one if the policyholder is alive in period $t+1$. An annuity of term $n$ issued in period $t$ pays out a constant stream of income

$$
D_{A, t+s}\left(n-s \mid h_{t+1}\right)=1_{\left\{h_{t+s} \neq 1\right\}}
$$

in each period $t+s \in[t+1, t+n]$ while the policyholder is alive. In each period $t, T-t$ is the maximum available term since the policyholder dies with certainty in period $T+1$.

The pricing of annuities depends on the policyholder's age and health at issuance of the policy. Naturally, younger and healthier policyholders with longer life expectancy pay a higher premium. Conditional on being in health state $h_{t}$ in period $t$, the price of an $n$-period

\footnotetext{
${ }^{3}$ The insurer could charge a premium that is independent of health in a pooling equilibrium (e.g., group life insurance). In that case, we would have to solve for a pooling price at which the insurer breaks even, given the aggregate demand for a given policy. While a conceptually straightforward extension of our framework, such an exercise would be computationally challenging. We refer to a related literature that examines the welfare implications of pooled pricing and private information in annuity and health insurance markets (Einav, Finkelstein, and Cullen, 2010; Einav, Finkelstein, and Schrimpf, 2010; Bundorf, Levin, and Mahoney, 2008).
} 
annuity per unit of income is

$$
P_{A, t}\left(n \mid h_{t}\right)=\sum_{s=1}^{n} \frac{q_{t}\left(s \mid h_{t}\right)}{R_{A}^{s}}
$$

where $R_{A} \leq R$ is the discount rate.

The annuities that we have introduced here are building blocks for so-called deferred annuities. In period $t$, suppose the policyholder goes long an annuity of term $T-t$ and short an annuity of term $n<T-t$. This long-short portfolio of annuities is effectively an $n$-period deferred annuity whose income payments start in period $t+n+1$.

\subsubsection{Supplementary Health Insurance}

Supplementary health insurance of term $n$ issued in period $t$ pays out a benefit of

$$
D_{H, t+s}\left(n-s \mid h_{t+s}\right)=1_{\left\{h_{t+s}=2\right\}}\left(M_{t+s}(2)-M_{t+s}(3)\right),
$$

in each period $t+s \in[t+1, t+n]$ while the policyholder is alive. Insofar as out-of-pocket health expenses include nursing home or home health care expenses, we can also interpret this policy as long-term care insurance. A unit of this policy represents full insurance, equating out-of-pocket health expenses across all health states in which the policyholder is alive. In each period $t, T-t$ is the maximum available term since the policyholder dies with certainty in period $T+1$.

The pricing of supplementary health insurance depends on the policyholder's age and health at issuance of the policy. Naturally, younger and healthier policyholders with lower expected health expenses pay a lower premium. Conditional on being in health state $h_{t}$ in period $t$, the price of $n$-period health insurance per unit of benefit is

$$
P_{H, t}\left(n \mid h_{t}\right)=\sum_{s=1}^{n} \frac{\pi_{t}^{s}\left(h_{t}, 2\right)\left(M_{t+s}(2)-M_{t+s}(3)\right)}{R_{H}^{s}}
$$


where $R_{H} \leq R$ is the discount rate.

\subsection{Health and Mortality Delta for Health and Longevity Prod- ucts}

For each policy $i=\{L, A, H\}$ of term $n$, we define its health delta in period $t$ as

$$
\Delta_{i, t}(n)=P_{i, t+1}(n-1 \mid 2)+D_{i, t+1}(n-1 \mid 2)-\left(P_{i, t+1}(n-1 \mid 3)+D_{i, t+1}(n-1 \mid 3)\right) .
$$

Health delta measures the differential payoff that a policy delivers in poor health relative to good health in period $t+1$. Similarly, we define its mortality delta in period $t$ as

$$
\delta_{i, t}(n)=D_{i, t+1}(n-1 \mid 1)-\left(P_{i, t+1}(n-1 \mid 3)+D_{i, t+1}(n-1 \mid 3)\right) .
$$

Mortality delta measures the differential payoff that a policy delivers at death relative to good health in period $t+1$.

Figure 2 explains the relation between the payoffs of a policy and its health and mortality delta. In this illustration, short-term policies have maturity of two years (i.e., the frequency of interviews in the Health and Retirement Study), while long-term policies mature at death. We normalize the death benefit of life insurance and the income payments from annuities to be $\$ 1 \mathrm{k}$. Section 4 contains details about how we calibrate the prices of long-term policies, which are not important for the purposes of this illustration. The solid line represents the payoffs of a policy in the three health states. Health delta is the payoff of a policy in poor health relative to good health, which is minus the slope of the dashed line if the horizontal distance between good and poor health is one. Mortality delta is the payoff of the policy at death relative to good health, which is minus two times the slope of the dotted line if the horizontal distance between good health and death is two.

Short-term life insurance pays out $\$ 1 \mathrm{k}$ only if the policyholder dies. Therefore, short-term 
life insurance has zero health delta and a mortality delta of $\$ 1 \mathrm{k}$. Even if the policyholder remains alive, long-term life insurance is worth the present value of $\$ 1 \mathrm{k}$ in the event of future death, which is higher in poor health when he has impaired mortality. Therefore, long-term life insurance has both positive health delta and positive mortality delta.

The short-term annuity pays out $\$ 1 \mathrm{k}$ only if the policyholder remains alive. Therefore, the short-term annuity has zero health delta and a mortality delta of $-\$ 1 \mathrm{k}$. In addition to the income if the policyholder remains alive, the long-term annuity is worth the present value of $\$ 1 \mathrm{k}$ in each future period that he remains alive, which is higher in good health when he has longer life expectancy. Therefore, the long-term annuity has both negative health delta and negative mortality delta.

Short-term health insurance pays out a benefit only in poor health when the policyholder has high out-of-pocket health expenses. Therefore, short-term health insurance has positive health delta and zero mortality delta. In addition to the benefit in poor health, long-term health insurance is worth the present value of benefits in the event of future poor health, which is higher in poor health when the policyholder has higher expected health expenses. Therefore, long-term health insurance has positive health delta and negative mortality delta.

Figure 3 reports the health and mortality delta per dollar investment for these health and longevity products over the life cycle. In comparison to long-term life insurance, shortterm life insurance generates high mortality delta per dollar investment. Therefore, shortterm life insurance is a relatively inexpensive way to deliver wealth to death, especially for younger policyholders. Short- and long-term annuities deliver similar mortality delta per dollar investment, implying that they are close substitutes. In comparison to longterm health insurance, short-term health insurance generates high health delta per dollar investment. Therefore, short-term health insurance is a relatively inexpensive way to deliver wealth to poor health, especially for younger policyholders. 


\subsection{Budget Constraint}

In each period $t$ that the household is alive, it receives labor or retirement income $Y_{t}$ and pays out-of-pocket health expenses $M_{t}$. The realization of both income and health expenses can depend on age and health. Let $W_{t}$ denote the household's cash-on-hand in period $t$, which is its wealth after receiving income and paying health expenses. The household consumes from cash-on-hand and saves the remaining wealth in life insurance, annuities, supplementary health insurance, and the bond. Let $B_{t}$ denote the total face value of bonds, and let $B_{i, t}(n) \geq 0$ denote the total face value of policy $i$ of term $n$. The household's savings in period $t$ is

$$
W_{t}-C_{t}=\frac{B_{t}}{R}+\sum_{i=\{L, A, H\}} \sum_{n=1}^{T-t} P_{i, t}\left(n \mid h_{t}\right) B_{i, t}(n)
$$

Let

$$
A_{t+1}(j)=B_{t}+\sum_{i=\{L, A, H\}} \sum_{n=1}^{T-t}\left(P_{i, t+1}(n-1 \mid j)+D_{i, t+1}(n-1 \mid j)\right) B_{i, t}(n)
$$

denote the household's wealth, prior to receiving income and paying health expenses, if health state $j$ is realized in period $t+1$. In particular, $A_{t+1}(1)=B_{t}+\sum_{n=1}^{T-t} B_{L, t}(n)$ is the wealth that is bequeathed if the household dies in period $t+1$. The household must die with non-negative net worth, that is $A_{t+1}(1) \geq 0$. The household's intertemporal budget constraint is

$$
W_{t+1}=A_{t+1}+Y_{t+1}-M_{t+1}
$$

\subsection{Loan from Health and Longevity Products}

The household can borrow from its holdings of health and longevity products, which we model as a negative position in the bond. For our purposes, a loan from health and longevity 
products is a simple way to model actual features of these policies. For example, long-term health insurance and life insurance may have periodic payment of premiums during the term of the policy, which can be interpreted as a "mortgage" on the policy. In addition, a household can take out a loan from the cash surrender value of whole-life insurance or a loan from annuities in a defined contribution plan.

For each policy $i$ of term $n$, the policyholder can borrow up to $\alpha_{i}(n) P_{i, t}\left(n \mid h_{t}\right)$ per unit of benefit, where $\alpha_{i}(n) \in[0,1]$. The loan accrues interest at the gross interest rate $R$. The policyholder can partially repay the loan including accrued interest at any time during the term of the policy. The policyholder must fully repay the loan at maturity of the policy or at death, whichever happens sooner. Hence, the household faces the borrowing constraint

$$
\frac{B_{t}}{R} \geq-\sum_{i=\{L, A, H\}} \sum_{n=1}^{T-t} \alpha_{i}(n) P_{i, t}\left(n \mid h_{t}\right) B_{i, t}(n)
$$

In addition, the household may face additional portfolio constraints, which we leave as unspecified in this general description of the life-cycle problem.

\subsection{Objective Function}

For each health state $h_{t} \in\{2,3\}$ in period $t$, we define the household's objective function recursively as

$$
U_{t}\left(h_{t}\right)=\left\{\omega\left(h_{t}\right)^{\gamma} C_{t}^{1-\gamma}+\beta\left[\pi_{t}\left(h_{t}, 1\right) \omega(1)^{\gamma} A_{t+1}(1)^{1-\gamma}+\sum_{j=2}^{3} \pi_{t}\left(h_{t}, j\right) U_{t+1}(j)^{1-\gamma}\right]\right\}^{1 /(1-\gamma)}
$$

with the terminal value

$$
U_{T}\left(h_{T}\right)=\omega\left(h_{T}\right)^{\gamma /(1-\gamma)} C_{T} .
$$


The parameter $\beta$ is the subjective discount factor, and $\gamma$ is relative risk aversion. The health state-dependent utility parameter $\omega\left(h_{t}\right)$ allows the marginal utility of consumption or wealth to vary across health states. The presence of a bequest motive is parameterized as $\omega(1)>0$, in contrast to its absence $\omega(1)=0$. The parameterization $\omega(2)<\omega(3)$ means that consumption and health are complements in the sense that the marginal utility of consumption is lower in poor health.

\section{Solution to the Life-Cycle Problem under Complete Markets}

In this section, we derive the solution to the life-cycle problem under complete markets. While markets may not be complete in practice, the closed-form solution that this assumption yields is a useful theoretical benchmark for thinking about the optimal management of health and mortality risk. We also derive a key formula for measuring the welfare cost of deviations from the optimal insurance of health and mortality risk.

\subsection{Optimal Health and Mortality Delta}

When markets are complete, there are potentially many portfolio policies that achieve the same consumption and wealth allocations. Therefore, it is impractical to characterize the optimal portfolio policy as a combination of health and longevity products. Instead, we characterize the solution to the life-cycle problem as an optimal consumption policy and a set of health state-contingent wealth policies.

To simplify notation, we define disposable income as income in excess of out-of-pocket

health expenses. We then define total wealth as cash-on-hand plus the present value of future 
disposable income:

$$
\widehat{W}_{t}=W_{t}+\sum_{s=1}^{T-t} \frac{\mathbf{E}_{t}\left[Y_{t+s}-M_{t+s} \mid h_{t}\right]}{R^{s}}
$$

We define health delta in period $t$ as the difference in wealth between poor and good health in period $t+1$ :

$$
\Delta_{t}=A_{t+1}(2)-A_{t+1}(3)
$$

Similarly, we define mortality delta in period $t$ as the difference in wealth between death and good health in period $t+1$ :

$$
\delta_{t}=A_{t+1}(1)-A_{t+1}(3)
$$

Proposition 1. When markets are complete, the solution to the life-cycle problem is

$$
\begin{aligned}
C_{t}^{*}= & c_{t}\left(h_{t}\right) \widehat{W}_{t}, \\
\Delta_{t}^{*}= & \frac{(\beta R)^{1 / \gamma} C_{t}^{*}}{\omega\left(h_{t}\right)}\left(\frac{\omega(2)}{c_{t+1}(2)}-\frac{\omega(3)}{c_{t+1}(3)}\right) \\
& -\left(\sum_{s=1}^{T-t} \frac{\mathbf{E}_{t+1}\left[Y_{t+s}-M_{t+s} \mid 2\right]}{R^{s-1}}-\sum_{s=1}^{T-t} \frac{\mathbf{E}_{t+1}\left[Y_{t+s}-M_{t+s} \mid 3\right]}{R^{s-1}}\right), \\
\delta_{t}^{*}= & \frac{(\beta R)^{1 / \gamma} C_{t}^{*}}{\omega\left(h_{t}\right)}\left(\omega(1)-\frac{\omega(3)}{c_{t+1}(3)}\right)+\sum_{s=1}^{T-t} \frac{\mathbf{E}_{t+1}\left[Y_{t+s}-M_{t+s} \mid 3\right]}{R^{s-1}} .
\end{aligned}
$$

The average propensity to consume in health state $h_{t} \in\{2,3\}$ is

$$
c_{t}\left(h_{t}\right)=\left[1+\frac{\pi_{t}\left(h_{t}, 1\right)(\beta R)^{1 / \gamma} \omega(1)}{R \omega\left(h_{t}\right)}+\sum_{j=2}^{3} \frac{\pi_{t}\left(h_{t}, j\right)(\beta R)^{1 / \gamma} \omega(j)}{R \omega\left(h_{t}\right) c_{t+1}(j)}\right]^{-1}
$$

with the terminal value $c_{T}\left(h_{T}\right)=1$.

As shown in Appendix A, the optimal policy equates the marginal utility of consumption 
or wealth across all health states in period $t+1$. The expression for the optimal health delta $\Delta_{t}^{*}$ shows that there are three forces that drive the household's desire to insure poor health relative to good health. First, the household would like to deliver relatively more wealth to the health state in which the marginal utility of consumption is high, determined by the relative magnitudes of $\omega(2)$ and $\omega(3)$. Second, the household would like to deliver relatively more wealth to the health state in which the average propensity to consume is low, determined by the relative magnitudes of $c_{t+1}(2)$ and $c_{t+1}(3)$. Naturally, the household consumes more slowly out of wealth in better health states associated with longer life expectancy. Finally, the household would like to deliver relatively more wealth to the health state in which lifetime disposable income is low. Naturally, the household has lower lifetime disposable income in poor health associated with shorter life expectancy, higher health expenses, and potentially lower income.

The same three forces also explain the expression for the optimal mortality delta $\delta_{t}^{*}$. First, the household would like to deliver relatively more wealth to death if the marginal utility of the bequest (i.e., $\omega(1)$ ) is high. Second, the household would like to deliver relatively more wealth to death if the average propensity to consume in good health (i.e., $\left.c_{t+1}(3)\right)$ is high. Finally, the household would like to deliver relatively more wealth to death if lifetime disposable income is high in good health.

\subsection{Replicating the Optimal Health and Mortality Delta through Health and Longevity Products}

Proposition 2. Given an optimal consumption policy, a feasible portfolio policy that satisfies the budget constraint (13), the borrowing constraint (16), and additional portfolio constraints 
(if any) is optimal if it satisfies the equations

$$
\begin{aligned}
\Delta_{t}^{*} & =\sum_{i=\{L, A, H\}} \sum_{n=1}^{T-t} \Delta_{i, t}(n) B_{i, t}(n), \\
\delta_{t}^{*} & =\sum_{i=\{L, A, H\}} \sum_{n=1}^{T-t} \delta_{i, t}(n) B_{i, t}(n) .
\end{aligned}
$$

Proposition 2 emphasizes the fact that health and mortality delta are sufficient for constructing an optimal portfolio of health and longevity products. Health delta $\Delta_{i, t}(n)$ measures the incremental contribution that policy $i$ of term $n$ has to the household's exposure to health delta. Mortality delta $\delta_{i, t}(n)$ measures the incremental contribution that policy $i$ of term $n$ has to the household's exposure to mortality delta. A combination of health and longevity products, not necessarily unique, that satisfies equation (26) delivers the optimal amount of wealth to poor health in period $t+1$. Similarly, a combination of health and longevity products, not necessarily unique, that satisfies equation (27) delivers the optimal amount of wealth to death in period $t+1$.

\subsection{Welfare Cost of Deviations from the Optimal Health and Mor- tality Delta}

Suppose the household's health and mortality delta were to deviate from the optimal health and mortality delta given in Proposition 1. As shown in Appendix A, we estimate the welfare cost of such deviations from the optimal health and mortality delta through a second-order Taylor approximation around the known value function under complete markets. By the envelope theorem, the welfare cost is second order for sufficiently small deviations from the optimal health and mortality delta (Cochrane, 1989).

Proposition 3. Let $V_{t}^{*}$ denote the value function associated with the sequence $\left\{\Delta_{t+s-1}^{*}(i), \delta_{t+s-1}^{*}(i)\right\}_{s=1}^{n}$ of optimal health and mortality delta under complete markets. Let $V_{t}$ denote the value function associated with an alternative sequence $\left\{\Delta_{t+s-1}(i), \delta_{t+s-1}(i)\right\}_{s=1}^{n}$ of health and mortality 
delta that satisfies the budget constraint. The welfare cost of deviations from the optimal health and mortality delta is

$$
\begin{aligned}
L_{t}(n)= & \frac{V_{t}}{V_{t}^{*}}-1 \\
\approx & \frac{1}{2} \sum_{s=1}^{n} \sum_{i=2}^{3}\left[\frac{\partial^{2} L_{t}(n)}{\Delta_{t+s-1}(i)^{2}}\left(\Delta_{t+s-1}(i)-\Delta_{t+s-1}^{*}(i)\right)^{2}\right. \\
& +\frac{\partial^{2} L_{t}(n)}{\delta_{t+s-1}(i)^{2}}\left(\delta_{t+s-1}(i)-\delta_{t+s-1}^{*}(i)\right)^{2} \\
& \left.+2 \frac{\partial^{2} L_{t}(n)}{\partial \Delta_{t+s-1}(i) \partial \delta_{t+s-1}(i)}\left(\Delta_{t+s-1}(i)-\Delta_{t+s-1}^{*}(i)\right)\left(\delta_{t+s-1}(i)-\delta_{t+s-1}^{*}(i)\right)\right],
\end{aligned}
$$

where the expressions for the second partial derivatives are given in Appendix A.

A household may not achieve the optimal health and mortality delta under complete markets for two reasons. First, markets may be incomplete due to borrowing or portfolio constraints, or the menu of health and longevity products may be incomplete for certain demographic groups. Second, a nearly rational household may hold a suboptimal portfolio of health and longevity products even though markets are complete (Calvet, Campbell, and Sodini, 2007). This explanation is especially plausible for health and longevity products because there is no clear guidance on optimal portfolio choice, unlike for equity and fixed-income products. Because these two reasons are not mutually exclusive and difficult to distinguish based on the available data, we do not attempt to quantify the relative importance of these two hypotheses. Instead, we focus on estimating the joint cost of market incompleteness and suboptimal portfolio choice in this paper.

\section{Calibrating the Life-Cycle Model}

\subsection{Health and Retirement Study}

We use the Health and Retirement Study to calibrate the life-cycle model, which is a repre-

sentative panel of older households in the United States since 1992. This household survey is 
uniquely suited for our study because it contains household-level data on health outcomes, health expenses, income, and wealth as well as ownership of life insurance, annuities, supplementary health insurance, and long-term care insurance. Some of these critical variables are missing in other household surveys such as the Panel Study of Income Dynamics or the Survey of Consumer Finances. We focus on households whose male respondent is aged 51 and older at the time of interview. We also require that households have both positive income and net worth to be included in our sample. Appendix B contains details on the construction of the relevant variables for our analysis.

Life insurance is written on the life of an individual, while resources like income and wealth are shared by the members of a household. Because the male respondent is typically married at the time of first interview, we must make some measurement assumptions when mapping the data to the model. We measure health outcomes and the ownership of life insurance, annuities, supplementary health insurance, and long-term care insurance for only the male respondent. We measure health expenses, income, and wealth at the household level. These measurement assumptions are consistent with our model insofar as the budget constraint holds for the household, and the male respondent buys life insurance to leave a bequest for surviving household members when he dies.

We calibrate the life-cycle model so that each period corresponds to two years, matching the frequency of interviews in the Health and Retirement Study. The model starts at age 51 to correspond to the youngest age at which respondents enter the survey. We assume that individuals die with certainty at age 111, so that there are a total of 30 periods (60 years) in the life-cycle model. We set the annualized riskless interest rate to 2 percent, which is roughly the average real return on the one-year Treasury note.

\subsection{Definition of the Health States}

In this section, we categorize health into three states including death, which is the minimum number of states necessary to model both health and mortality risk. For our purposes, the 
relevant criteria for poor health are that both the mortality rate and health expenses are high. This is precisely the state in which life insurance and supplementary health insurance are valuable.

In Table 2, we use a probit model to predict future mortality based on observed health problems. The explanatory variables include dummy variables for doctor-diagnosed health problems, age, the interaction of the health problems with age, and cohort dummies. The marginal effect of high blood pressure on the mortality rate is 1.66 with a $t$-statistic of 3.52 . This means that individuals with high blood pressure are 1.66 percentage points more likely to die within two years, holding everything else constant. Individuals with cancer are 13.62 percentage points more likely to die, while those with lung disease are 8.21 percentage points more likely to die. Past age 51, each additional ten years is associated with an increase of 3.26 percentage points in the mortality rate.

Using the estimated probit model, we calculate the predicted mortality rate for each male respondent at each interview. We also calculate the ratio of out-of-pocket health expenses to income at each interview. We then define the following three health states.

\section{Death.}

2. Poor health: The predicted mortality rate is higher than the median conditional on cohort and age. In addition, the ratio of out-of-pocket health expenses to income is higher than the median conditional on cohort, age, and the ownership of supplementary health insurance and long-term care insurance.

3. Good health: Alive and not in poor health.

To verify that our definition of the health states are reasonable, Panel A of Table 3 reports specific health problems that individuals face by age group and health state. Within each age group, individuals in poor health have higher prevalence of doctor-diagnosed health problems. For example, among individuals aged 51 to 66,28 percent of those in poor health have had heart problems, which is higher than 11 percent of those in good health. Older 
individuals, especially those in poor health, have higher prevalence of difficulty with activities of daily living. For example, among individuals aged 83 or older, 16 percent of those in poor health have some difficulty eating, which is higher than 7 percent of those in good health.

Panel B of Table 3 reports health care utilization by age group and health state. Within each age group, individuals in poor health are more likely to have used health care in the two years prior to the interview. For example, among individuals aged 51 to 66, 79 percent of those in poor health use prescription drugs regularly, which is higher than 52 percent of those in good health. Among individuals aged 83 or older, 19 percent of those in poor health have stayed at a nursing home, which is higher than 8 percent of those in good health. These facts explain why households in poor health have higher out-of-pocket health expenses than those in good health.

Panel $\mathrm{C}$ of Table 3 reports health insurance coverage by age group and health state. Among individuals aged 51 to 66, 22 percent of those in poor health are covered by Medicare, which is higher than 17 percent of those in good health. This difference is explained by the fact that some individuals who are disabled become eligible for Medicare prior to age 65 . Almost all individuals aged 67 or older are covered by Medicare. Among individuals aged 51 to 66,58 percent of those in poor health are covered by an employer-provided health plan, which is lower than 63 percent of those in good health. Within each age group, the ownership rates of supplementary health insurance and long-term care insurance are remarkably similar across health states.

Panel D of Table 3 reports the ownership rate of life insurance, the ownership rate of annuities including private pensions, and net worth by age group and health state. Among individuals aged 51 to 66, 78 percent of those in poor health own some type of life insurance, which is comparable to 80 percent of those in good health. Although the ownership rate for life insurance declines in age, it remains remarkably high for older individuals. Among individuals aged 67 to 82,56 percent of those in poor health receive annuity income that is not from Social Security, which is comparable to 54 percent of those in good health. Among 
individuals aged 67 to 82, the median net worth excluding life insurance and annuities is $\$ 186 \mathrm{k}$ for those in poor health, which is comparable to $\$ 187 \mathrm{k}$ for those in good health.

\subsection{Health and Mortality Risk}

\subsubsection{Health Transition Probabilities}

Once we have defined the three health states, we estimate the transition probabilities between the health states using an ordered probit model. The outcome variable is the health state at two years from the present interview. The explanatory variables include dummy variables for present health state and 65 or older, a quadratic polynomial in age, the interaction of the dummy variables with age, and cohort dummies. The dummy variable for 65 or older allows for potential changes in household behavior when they become eligible for Social Security and Medicare. Our estimated transition probabilities, which are cohort-specific, are the predicted probabilities from the ordered probit model.

To get a sense for these transition probabilities, Panel A of Table 4 reports the health distribution by age for a population of individuals born 1936 to 1940, who are in good health at age 51 . By age 67, 30 percent of the population are dead, and 18 percent are in poor health. By age 83, 62 percent of the population are dead, and 14 percent are in poor health. Panel B reports the average life expectancy conditional on age and health. ${ }^{4}$ Individuals in poor health at age 51 are expected to live for 24 more years, which is shorter than 26 years for those in good health. The difference in life expectancy between poor and good health remains relatively constant for older individuals. Individuals in poor health at age 83 are expected to live for 8 more years, which is shorter than 10 years for those in good health.

\footnotetext{
${ }^{4}$ For comparison, the corresponding estimates of life expectancy from the Social Security cohort life tables are 28 years at age 51, 21 years at age 59,16 years at age 67,11 years at age 75,7 years at age 83,4 years at age 91 , and 2 years at age 99 .
} 


\subsubsection{Out-of-Pocket Health Expenses}

We use a comprehensive measure of out-of-pocket health expenses that includes payments of health insurance premiums and end-of-life health expenses. As explained in Appendix B, we use a panel regression model to estimate how out-of-pocket health expenses depend on cohort, age, health, and income. Panel $\mathrm{C}$ of Table 4 reports average annual out-of-pocket health expenses by age and health for the cohort born 1936 to 1940. For comparison, Panel D reports average annual income by age, which includes Social Security but excludes annuities and private pensions. ${ }^{5}$ Households in poor health at age 51 have annual out-ofpocket health expenses of $\$ 2 \mathrm{k}$, which is higher than $\$ 0 \mathrm{k}$ for those in good health. Out-ofpocket health expenses rise rapidly in age, as emphasized by De Nardi, French, and Jones (2010). Households in poor health at age 83 have annual out-of-pocket health expenses of $\$ 21 \mathrm{k}$, which is higher than $\$ 7 \mathrm{k}$ for those in good health. Since annual income at age 83 is $\$ 18 \mathrm{k}$, households in poor health must dissave in order to consume and pay health expenses.

Households in poor health not only face higher health expenses today, but they also face higher future health expenses. Panel E of Table 4 reports the present value of future disposable income (i.e., income in excess of out-of-pocket health expenses) by age and health. Households in poor health at age 59 have $\$ 232 \mathrm{k}$ in lifetime disposable income that they can consume or bequeath, which is lower than $\$ 270 \mathrm{k}$ for those in good health. An individual in good health at age 51 is unlikely to be in poor health or die, at least in the near future. However, poor health or death can have a significant impact on lifetime resources. This leads to demand for health and longevity products that allow households to insure uncertainty in lifetime resources across health states.

\footnotetext{
${ }^{5}$ For simplicity, our calibration assumes that income depends on cohort and age, but not on health. While there is some evidence that income varies with health, such variation is much smaller than the variation in out-of-pocket health expenses, which is our main focus.
} 


\subsection{Pricing of Health and Longevity Products}

In our baseline calibration, we set the discount rate on health and longevity products to be the same as the riskless interest rate of 2 percent (i.e., $R_{L}=R_{A}=R_{H}=R$ ). In other words, we assume that the pricing of health and longevity products is actuarially fair conditional on age and health. This simplifying assumption is necessitated by the fact that we do not

observe the premiums that households in the data pay for life insurance, supplementary health insurance, and long-term care insurance. There are various reasons why the pricing of health and longevity products may not be actuarially fair in practice: rents arising from imperfect competition, discounts reflecting the poor credit quality of insurers, risk premia arising from aggregate health and mortality risk, and the presence of private information. To capture these scenarios, we consider an alternative calibration in which health and longevity products are more expensive than actuarially fair in Section 5 .

The impact of private information on the pricing of insurance is ambiguous because adverse selection on health may be offset by advantageous selection on another dimension of private information such as risk aversion (de Meza and Webb, 2001). In life insurance markets, there is no evidence for private information about health (Cawley and Philipson, 1999). Because the pricing of annuities depends on gender and age but not on health, annuity markets may be in a separating equilibrium along contract dimensions like payout structure (Finkelstein and Poterba, 2004). In long-term care and Medigap insurance markets, private information about health appears to be offset by advantageous selection on risk aversion and cognitive ability (Finkelstein and McGarry, 2006; Fang, Keane, and Silverman, 2008). Given the ambiguous nature of both the theoretical predictions and the empirical findings, the absence of private information serves as a satisfactory starting point for our baseline calibration. However, we examine private information as a potential explanation for the heterogeneity in demand for health and longevity products in our empirical work. 


\subsection{Ownership of Health and Longevity Products}

At each interview, individuals report their ownership of term- and whole-life insurance, annuities including private pensions, supplementary health insurance, and long-term care insurance. We do not have information about the maturity of term-life insurance or the exact coverage of supplementary health insurance or long-term care insurance. Therefore, we must make some measurement assumptions in order to map these health and longevity products to counterparts in the life-cycle model.

We assume that term-life insurance matures in two years and that whole-life insurance matures at death. The assumption that term-life insurance is short term is motivated by the fact that group policies account for a large share of these policies. We assume that annuity income starts at age 65, which is the full Social Security retirement age, and terminates at death. We assume that the observed ownership of supplementary health insurance corresponds to owning half a unit of short-term health insurance in the life-cycle model. Similarly, the observed ownership of long-term care insurance corresponds to owning half a unit of short-term health insurance. Therefore, a household that owns both supplementary health insurance and long-term care insurance is fully insured against out-of-pocket health expenses for one period. This assumption is based on estimates that nursing home expenses account for approximately half of out-of-pocket health expenses for older households (Marshall, McGarry, and Skinner, 2011).

Conditional on ownership, individuals report the face value of term- and whole-life insurance. Measurement error in the face value of these policies would contaminate our estimates of health and mortality delta. As explained in Appendix B, we use a panel regression model to estimate how the face values of term- and whole-life insurance depend on cohort, age, health, and income. Instead of using the observed face values, we use the predicted values with household fixed effects under the assumption that measurement error is transitory. We apply the same procedure to annuity and pension income.

We model all health and longevity products as policies with real payments. We normal- 
ize the death benefit of life insurance and the income payments from annuities to be $\$ 1 \mathrm{k}$ in 2005 dollars. Modeling nominal payments for health and longevity products would introduce inflation risk, which is beyond the scope of this paper. Moreover, a cost-of-living-adjustment rider that effectively eliminates inflation risk is sometimes available for life insurance, annuities, and long-term care insurance. In the data, we deflate the face value of life insurance as well as pension and annuity income by the consumer price index to 2005 dollars.

\section{Welfare Cost of Household Insurance Choice}

In this section, we calculate health and mortality delta for each household, implied by its ownership of health and longevity products. We then examine to what extent observed household characteristics explain the variation in health and mortality delta. Finally, we apply Proposition 3 to estimate the welfare cost of market incompleteness and suboptimal portfolio choice.

\subsection{Health and Mortality Delta Implied by Household Insurance Choice}

For each household at each interview, we calculate the health and mortality delta implied by its ownership of term- and whole-life insurance, annuities including private pensions, supplementary health insurance, and long-term care insurance. A household's overall exposure to health delta is determined by positive health delta from whole-life insurance, supplementary health insurance, and long-term care insurance, which is offset by negative health delta from deferred annuities. A household's overall exposure to mortality delta is determined by positive mortality delta from term- and whole-life insurance, which is offset by negative mortality delta from deferred annuities.

Figure 4 reports the health and mortality delta for each household-interview observation, together with the median and mean at each age. Average health delta is slightly negative 
throughout the life cycle. This means that annuities have a predominant effect on the average household's exposure to health delta. Average mortality delta is positive for younger households and negative for older households. This means that life insurance has a predominant effect on younger households' exposure to mortality delta, while annuities have a predominant effect for older households. The variation in mortality delta is significantly higher than that for health delta throughout the life cycle.

\subsection{Determinants of Health and Mortality Delta}

In Table 5, we examine to what extent observed household characteristics explain the variation in health and mortality delta. In the baseline specification in column (1), we regress health delta onto dummy variables for poor health and 65 or older, a quadratic polynomial in age, the interaction of the dummy variables with age, and cohort dummies. These explanatory variables that capture life-cycle effects explain only 7 percent of the variation in health delta. In other words, the remaining 93 percent of the variation in health delta must be explained by elements that are outside the life-cycle model.

In column (2), we include additional explanatory variables that capture potential heterogeneity in bequest motives, risk aversion, and private information about health. Marital status and children are insignificant determinants of health delta, which suggests that heterogeneity in bequest motives do not explain the variation in health delta. Health delta for college graduates is $\$ 3.27 \mathrm{k}$ higher than that for non-high school graduates, which implies that education has some role in explaining health delta. Health delta for households in poor self-reported health is $\$ 1.16 \mathrm{k}$ higher than that for those in good self-reported health, which is consistent with the presence of private information about health. However, health delta for households in excellent self-reported health is $\$ 1.90 \mathrm{k}$ higher than that for those in good self-reported health. Overall, the $R^{2}$ of the regression is only 13 percent, which implies a significant amount of unexplained variation in health delta.

We repeat the same exercise for mortality delta in columns (3) and (4). The baseline 
specification in column (3) explains only 12 percent of the variation in mortality delta. In column (4), mortality delta is $\$ 42.60 \mathrm{k}$ higher for married households and $\$ 33.49 \mathrm{k}$ higher for households with living children. The sign of these coefficients are consistent with the hypothesis that the bequest motive is stronger for married households and those with living children. Mortality delta for college graduates is $\$ 126.00 \mathrm{k}$ higher than that for non-high school graduates, which implies that education has some role in explaining mortality delta. Mortality delta for households in poor self-reported health is $\$ 39.46 \mathrm{k}$ higher than that for those in good self-reported health. Similarly, mortality delta for households in excellent self-reported health is $\$ 11.77 \mathrm{k}$ lower than that for those in good self-reported health. This evidence is consistent with the presence of private information about health. Overall, the $R^{2}$ of the regression is only 16 percent, which implies a significant amount of unexplained variation in mortality delta. ${ }^{6}$

In summary, we find that observed household characteristics that capture potential heterogeneity in bequest motives, risk aversion, and private information about health do not explain much of the variation in health and mortality delta. However, we cannot rule out the presence of unobserved heterogeneity that is uncorrelated with observed household characteristics (Fang and Kung, 2010). This finding suggests that preference heterogeneity along observable dimensions of household characteristics would not be able to explain the welfare cost of household insurance choice that we document next.

\subsection{Per-Period Welfare Cost}

In this section, we estimate the welfare cost of deviating from the optimal health and mortality delta in the first period, then following the optimal policy for the remaining lifetime. While the per-period welfare cost is not our primary measure of interest, it allows us to

\footnotetext{
${ }^{6}$ We have also ruled out significant explanatory power for other variables that capture potential heterogeneity in bequest motives (i.e., net worth and self-reported probability of leaving a bequest), risk aversion (i.e., responses to income gamble questions), and private information about health (i.e., difficulty with activities of daily living, self-reported probability of living to age 75 , and self-reported probability of moving to a nursing home).
} 
estimate the preference parameters based on the observed ownership of health and longevity products alone, without an auxiliary model for how such ownership may evolve over time.

For a given set of preference parameters, we can calculate the per-period welfare cost by applying Proposition 3 for $n=1$. We set the subjective discount factor to $\beta=0.96$ annually, which is a common choice in the life-cycle literature. We set relative risk aversion to $\gamma=4$, based on previous estimates in the Health and Retirement Study (Barsky et al., 1997). There is less guidance in the literature for the health state-dependent utility parameters. Therefore, we estimate $\omega(1)$ and $\omega(2)$ to minimize the implied welfare cost, under the normalization $\omega(3)=1$. Our procedure leads to a lower-bound estimate of the per-period welfare cost under the true preference parameters.

Let $L_{h}(\omega(1), \omega(2))$ denote the per-period welfare cost for household-interview observation $h \in[1, H]$, given the preference parameters $\omega(1)$ and $\omega(2)$. We estimate the preference parameters by minimizing the sum of the welfare cost across all observations:

$$
\frac{1}{H} \sum_{h=1}^{H} L_{h}(\omega(1), \omega(2)) .
$$

We use continuous-updating generalized method of moments, based on the moment restriction

$$
\mathbf{E}\left[\begin{array}{c}
\frac{\partial L_{h}(\omega(1), \omega(2))}{\partial \omega(1)} \\
\frac{\partial L_{h}(\omega(1), \omega(2))}{\partial \omega(2)}
\end{array}\right]=\mathbf{0} .
$$

As reported in Table 6 , we obtain an estimate $\omega(1)=5.00$ with a standard error of 0.13. In other words, households have a bequest motive that is equivalent to 5 periods (10 years) of consumption. This strong bequest motive is consistent with previous estimates in the literature (Ameriks et al., 2011). We also obtain an estimate of $\omega(2)=0.84$ with a standard error of 0.02. The fact that consumption and health are complements is consistent with previous estimates in the literature (Viscusi and Evans, 1990; Finkelstein, Luttmer, and 
Notowidigdo, 2008).

Panel A of Table 7 reports the median per-period welfare cost by age group. The perperiod (two-year) welfare cost for households aged 51 to 58 is 0.87 percent with a standard error of 0.09 percent. Using equation (28) for $n=1$, we decompose this welfare cost into the sum of three parts. Deviations of the observed health delta from the optimal health delta explains 0.02 percent, while deviations of the observed mortality delta from the optimal mortality delta explains 0.87 percent. The interaction between health and mortality delta explains -0.02 percent, which is the remainder of the per-period welfare cost. The perperiod welfare cost remains relatively stable in age, although health delta explains a more important share of the welfare cost for older households.

The top three panels of Figure 5 reports the per-period welfare cost and its decomposition for each household-interview observation, together with the median at each age. There is significant heterogeneity in the per-period welfare cost across households, implied by their insurance choice. To better understand the source of this heterogeneity, Figure 6 divides the population of households into three groups. The first group consists of households whose mortality delta is higher than the optimal mortality delta. These households are essentially under-annuitized and contribute to the so-called annuity puzzle in the literature. The second group consists of households whose mortality delta is lower than the optimal mortality delta. These households are essentially over-annuitized, given the estimated bequest motive, and should be buying life insurance to offset the excess annuitization imposed by Social Security and private pensions (Bernheim, 1991). The third group consists of households whose

mortality delta is so low that their degree of annuitization is excessive even if they had no bequest motive.

\subsection{Lifetime Welfare Cost}

The per-period welfare cost is based on the assumption that the household deviates from the optimal health and mortality delta for the first period, then follows the optimal policy for 
the remainder of its lifetime. In reality, a household that deviates from the optimal policy for one period will persist in the suboptimal policy for many periods. In this section, we measure the lifetime welfare cost by applying Proposition 3 for $n=T-t$.

In order to measure the lifetime cost, we must first model how the ownership of health and longevity products evolves over time, exploiting the panel dimension of the data. In Table 8, we use a probit model to predict ownership of a given type of policy at two years from the present interview. The key explanatory variable is whether the individual is a present policy owner. Individuals aged 51 that are present owners of term-life insurance are 46 percentage points more likely to own it at the next interview. Similarly, individuals aged 51 that are present owners of whole-life insurance are 67 percentage points more likely to own it at the next interview. Individuals aged 51 that are present owners of annuities including private pensions are 53 percentage points more likely to own them at the next interview. Individuals aged 51 that are present owners of supplementary health insurance are 33 percentage points more likely to own it at the next interview. Finally, individuals aged 51 that are present owners of long-term care insurance are 24 percentage points more likely to own it at the next interview.

Based on the predicted probabilities from the probit model, we calculate the joint transition matrix for the health state and the ownership of health and longevity products. For each individual, we then calculate the most likely sequence of future ownership of health and longevity products, conditional on the realized health state. Finally, we calculate the sequence of future health and mortality delta implied by the ownership of health and longevity products (i.e., $\left\{\Delta_{t+s-1}(i), \delta_{t+s-1}(i)\right\}_{s=2}^{T-t}$ in Proposition 3).

Panel B of Table 7 reports the median lifetime welfare cost by age group. The lifetime welfare cost for households aged 51 to 58 is 28.49 percent with a standard error of 0.51 percent. This is a significant welfare cost that is equivalent to a 28 percent reduction in lifetime consumption, as implied by the homogeneity of preferences. Using equation (28) for $n=T-t$, we decompose this welfare cost into the sum of three parts. Deviations of the 
observed health delta from the optimal health delta explain 0.77 percent, while deviations of the observed mortality delta from the optimal mortality delta explain 29.61 percent. The interaction between health and mortality delta explains -1.89 percent, which is the remainder of the lifetime welfare cost. The lifetime welfare cost for households aged 83 to 90 is 2.89 percent with a standard error of 0.38 percent. Health delta explains 0.58 percent of this welfare cost, while mortality delta explains 3.53 percent.

The bottom three panels of Figure 5 reports the lifetime welfare cost and its decomposition for each household-interview observation, together with the median at each age. The lifetime welfare cost is higher for younger households, for whom the per-period welfare cost accumulates over a longer expected lifetime. The lifetime welfare cost declines rapidly until age 83 and becomes small for older households with shorter life expectancy. Mortality delta explains almost all of the lifetime welfare cost because there is significantly more variation in mortality delta than in health delta.

\subsection{Lifetime Welfare Cost under Alternative Assumptions}

In Table 9, we examine the robustness of our main conclusions to alternative assumptions about preferences and the pricing of health and longevity products. On the one hand, a weaker bequest motive of $\omega(1)=4$ leads to a per-period welfare cost that is slightly higher and a lifetime welfare cost that is significantly higher than the baseline estimate in Table 7 . On the other hand, a stronger bequest motive of $\omega(1)=6$ leads to a per-period welfare cost that is higher for younger households and lower for older households. This points to a tension that a sufficiently weak bequest motive that matches the mortality delta for younger households causes the model to predict a mortality delta for older households that is too low relative to the data. Put differently, the bequest motive would have to strengthen over the life cycle in order for the model to match the life-cycle profile for mortality delta in Figure 4. Under the stronger bequest motive, the lifetime welfare cost for households aged 51 to 58 is 24.25 percent, which is slightly lower than the baseline estimate. 
Table 9 also examines scenarios in which the pricing of health and longevity products is more expensive than actuarially fair. We assume that the discount rate (or the expected return) on life insurance, annuities, and supplementary health insurance is 0 percent when the riskless interest rate is 2 percent. This is a fairly extreme assumption that corresponds to the upper range of deviations from actuarially fair pricing that is estimated for the annuity market (Mitchell et al., 1999). Both the per-period and the lifetime welfare costs are essentially the same as the baseline estimate in Table 7. Our main conclusions are therefore robust to alternative assumptions about the pricing of health and longevity products.

\section{Replicating the Optimal Health and Mortality Delta}

In this section, we illustrate how a household can replicate the optimal health and mortality delta through existing health and longevity products, such as those in Table 1. Our illustration is for a male in good health at age 51, born 1936 to 1940. The household's initial wealth is $\$ 65 \mathrm{k}$ at age 51 , which is chosen to match average net worth excluding life insurance and annuities for this cohort. The household can buy short-term life insurance, a deferred annuity, short-term health insurance, and a bond. We do not impose any borrowing or portfolio constraints, so that the household achieves the optimal health and mortality delta under complete markets. The household's preference parameters are those given in Table 6 .

Panel A of Table 10 reports the optimal health and mortality delta, which we calculate by applying Proposition 1 . The optimal health delta is $\$ 7 \mathrm{k}$ at age 51 , which implies that the household needs an additional $\$ 7 \mathrm{k}$ in poor health relative to good health at age 53 . As equation (23) shows, there are three offsetting forces that determine the optimal health delta. First, the household has preference for consumption in good health over poor health (i.e., $\omega(2)<\omega(3)$ ), which pushes the optimal health delta to be more negative. Second, the household saves less in poor health because of shorter life expectancy (i.e., $c_{t+1}(2)>c_{t+1}(3)$ ), which pushes the optimal health delta to be more negative. Third, the household has lower 
lifetime disposable income in poor health, which pushes the optimal health delta to be more positive. The third force dominates the first two so that the optimal health delta is positive at age 51 .

The optimal mortality delta is $\$ 188 \mathrm{k}$ at age 51 , which implies that the household needs an additional $\$ 188 \mathrm{k}$ at death relative to good health at age 53. As equation (24) shows, there are three offsetting forces that determine the optimal mortality delta. First, the household has preference for bequest over consumption in good health (i.e., $\omega(1)>\omega(3)$ ), which pushes the optimal mortality delta to be more positive. Second, the household must save for future consumption in good health (i.e., $c_{t+1}(3)<1$ ), which pushes the optimal mortality delta to be more negative. Third, the household has higher lifetime disposable income in good health, which pushes the optimal mortality delta to be more positive. The first and third forces dominate the second so that the optimal mortality delta is positive at age 51 .

Panel B of Table 10 reports a portfolio of short-term life insurance, deferred annuities, and short-term health insurance that replicates the optimal health and mortality delta, which we calculate by applying Proposition 2. The optimal portfolio at age 51 consists of 188 units (i.e., death benefit of $\$ 188 \mathrm{k}$ ) of short-term life insurance, 1.80 units of short-term health insurance, and 60 units of the bond. A portfolio of only short-term policies leads to clean separation between health insurance that replicates the optimal health delta and life insurance that replicates the optimal mortality delta. Panel $\mathrm{C}$ reports the cost of the optimal portfolio, which is the sum of $\$ 5 \mathrm{k}$ in short-term life insurance, $\$ 2 \mathrm{k}$ in short-term health insurance, and $\$ 58 \mathrm{k}$ in bonds.

The left panel of Figure 7 shows that the optimal health delta has a U-shaped profile over the life cycle. The position in short-term health insurance that replicates the optimal health delta is 1.80 units at age 51, 0.07 units at age 67, and 0.77 units at age 83 . Since one unit of short-term health insurance eliminates all uncertainty in out-of-pocket health expenses in the next period, these positions imply that the household demands only partial health insurance for most of the life cycle. The intuition for this result is that higher out-of-pocket 
health expenses in poor health are offset by shorter life expectancy, lowering the optimal health delta relative to full health insurance.

The right panel of Figure 7 shows that the optimal mortality delta declines over the life cycle. To replicate the optimal mortality delta, the household must hold short-term life insurance when young to generate positive mortality delta, then switch to deferred annuities when old to generate negative mortality delta. The optimal position in deferred annuities increases from 17 units (i.e., annuity income of $\$ 17 \mathrm{k}$ over two years) at age 59 to 125 units at age 83. The life-cycle profile for optimal mortality delta suggest that insurance companies may want to package life insurance and annuities into a "life-cycle product" that automatically switches from life insurance to annuities around retirement age.

In this illustration, the household is exposed to reclassification risk because it can only invest in short-term life insurance and health insurance. In other words, a household in good health at age 51 has to pay a higher premium for life insurance and health insurance at age 53 if its health deteriorates. As emphasized by Cochrane (1995), the household can insure reclassification risk in a world with health state-contingent securities. Our illustration here shows that an optimal portfolio of short-term life insurance and health insurance essentially replicates health state-contingent securities, thereby insuring reclassification risk.

\section{Conclusion}

We have developed health and mortality delta as useful risk measures for thinking about health and longevity products such as life insurance, annuities, and supplementary health insurance. We believe that retail financial advisors and insurance companies should report the health and mortality delta of their health and longevity products, just as mutual fund companies report the market beta of their equity products and the duration of their fixedincome products. Financial advisors and insurance brokers should guide households on the optimal exposure to health and mortality delta over the life cycle, based on their preferences 
(e.g., risk aversion and bequest motive) and characteristics (e.g., birth cohort, age, health, and wealth). We hope that the introduction of these risk measures will facilitate standardization, identify overlap between existing products, identify risks that are not insured by existing products, and ultimately lead to new product development.

There are two potential interpretations for our estimate of the welfare cost of household insurance choice. Our preferred interpretation is that there are significant welfare gains that can be achieved by completing missing insurance markets and by eliminating suboptimal portfolio choice. The existence of suboptimal portfolio choice is plausible for health and longevity products because there is no clear guidance on optimal portfolio choice, unlike for equity and fixed-income products. An alternative interpretation is the existence of unobserved preference heterogeneity. We are skeptical of this possibility because our empirical findings suggest that such preference heterogeneity must be entirely unrelated to observable proxies for bequest motives, risk aversion, and private information about health. 


\section{Appendix A. Proof of the Propositions}

\section{A.1 Proof of Proposition 1}

We rewrite savings in period $t$ as

$$
W_{t}-C_{t}=\sum_{j=1}^{3} \frac{\pi_{t}\left(h_{t}, j\right)}{R} A_{t+1}(j) .
$$

The household maximizes the objective function (17) subject to equation (A1) and the intertemporal budget constraint (15). In each period $t \in[1, T-1]$, the Bellman equation is

$$
\begin{aligned}
V_{t}\left(h_{t}, W_{t}\right)= & \max _{C_{t}, A_{t+1}(1), A_{t+1}(2), A_{t+1}(3)}\left\{\omega\left(h_{t}\right)^{\gamma} C_{t}^{1-\gamma}\right. \\
& \left.+\beta\left[\pi_{t}\left(h_{t}, 1\right) \omega(1)^{\gamma} A_{t+1}(1)^{1-\gamma}+\sum_{j=2}^{3} \pi_{t}\left(h_{t}, j\right) V_{t+1}\left(j, W_{t+1}(j)\right)^{1-\gamma}\right]\right\}^{1 / 1-\gamma} .
\end{aligned}
$$

The proposition claims that the optimal health state-contingent wealth policies are given by

$$
\begin{aligned}
& A_{t+1}^{*}(1)=\frac{(\beta R)^{1 / \gamma} \omega(1) C_{t}^{*}}{\omega\left(h_{t}\right)}, \\
& A_{t+1}^{*}(j)=\frac{(\beta R)^{1 / \gamma} \omega(j) C_{t}^{*}}{\omega\left(h_{t}\right) c_{t+1}(j)}-\sum_{s=1}^{T-t} \frac{\mathbf{E}_{t+1}\left[Y_{t+s}-M_{t+s} \mid j\right]}{R^{s-1}} \forall j \in\{2,3\} .
\end{aligned}
$$

The proof proceeds by backward induction.

Because the household dies with certainty in period $T+1$, optimal consumption in period $T$ is $C_{T}^{*}=W_{T}$. Thus, the value function in period $T$ is

$$
V_{T}\left(h_{T}, W_{T}\right)=\omega\left(h_{T}\right)^{\gamma /(1-\gamma)} W_{T}
$$


The first-order conditions in period $T-1$ are

$$
\begin{aligned}
\omega\left(h_{T-1}\right)^{\gamma} C_{T-1}^{*-\gamma} & =\beta R \omega(1)^{\gamma} A_{T}^{*}(1)^{-\gamma} \\
& =\beta R \omega\left(h_{T}\right)^{\gamma}\left(A_{T}^{*}(j)+Y_{T}(j)-M_{T}(j)\right)^{-\gamma} \forall j \in\{2,3\} .
\end{aligned}
$$

These equations, together with equation (A1), imply the policy functions (22), (A3), and (A4) for period $T-1$. Substituting the policy functions into the Bellman equation, the value function in period $T-1$ is

$$
V_{T-1}\left(h_{T-1}, W_{T-1}\right)=\left(\frac{\omega\left(h_{T-1}\right)}{c_{T-1}\left(h_{T-1}\right)}\right)^{\gamma /(1-\gamma)} \widehat{W}_{T-1} .
$$

Suppose that the value function in each period $t+1$ is

$$
V_{t+1}\left(h_{t+1}, W_{t+1}\right)=\left(\frac{\omega\left(h_{t+1}\right)}{c_{t+1}\left(h_{t+1}\right)}\right)^{\gamma /(1-\gamma)} \widehat{W}_{t+1} .
$$

The first-order conditions in each period $t$ are

$$
\begin{aligned}
\omega\left(h_{t}\right)^{\gamma} C_{t}^{*-\gamma} & =\beta R \omega(1)^{\gamma} A_{t+1}^{*}(1)^{-\gamma} \\
& =\frac{\beta R \omega(j)^{\gamma}}{c_{t+1}(j)^{\gamma}}\left(A_{t+1}^{*}(j)+\sum_{s=1}^{T-t} \frac{\mathbf{E}_{t+1}\left[Y_{t+s}-M_{t+s} \mid j\right]}{R^{s-1}}\right)^{-\gamma} \forall j \in\{2,3\} .
\end{aligned}
$$

These equations, together with equation (A1), imply the policy functions (22), (A3), and (A4) for each period $t$. Substituting the policy functions into the Bellman equation, the value function in each period $t$ is

$$
V_{t}\left(h_{t}, W_{t}\right)=\left(\frac{\omega\left(h_{t}\right)}{c_{t}\left(h_{t}\right)}\right)^{\gamma /(1-\gamma)} \widehat{W}_{t}
$$




\section{A.2 Proof of Proposition 3}

To simplify notation, let $\pi_{t}^{0}\left(h_{t}, i\right)=1_{\left\{h_{t}=i\right\}}$. Iterating forward on the budget constraint (A1),

$$
\begin{aligned}
W_{t}-C_{t}= & \sum_{s=1}^{n-1} \sum_{i=2}^{3} \frac{\pi_{t}^{s}\left(h_{t}, i\right)}{R^{s}}\left(C_{t+s}(i)-Y_{t+s}(i)+M_{t+s}(i)\right) \\
& +\sum_{s=1}^{n} \sum_{i=2}^{3} \frac{\pi_{t}^{s-1}\left(h_{t}, i\right) \pi_{t+s-1}(i, 1)}{R^{s}}\left(\delta_{t+s-1}(i)+A_{t+s}(i)\right) \\
& +\sum_{i=2}^{3}\left[\frac{\pi_{t}^{n-1}\left(h_{t}, i\right) \pi_{t+n-1}(i, 2)}{R^{n}}\left(\Delta_{t+n-1}(i)+A_{t+n}(i)\right)\right. \\
& \left.+\frac{\pi_{t}^{n-1}\left(h_{t}, i\right) \pi_{t+n-1}(i, 3)}{R^{n}} A_{t+n}(i)\right]
\end{aligned}
$$

We consider perturbations of health and mortality delta that satisfy the budget constraint:

$$
\begin{gathered}
\partial \Delta_{t+n-1}(i)+\pi_{t+n-1}(i, 2) \partial A_{t+n}(i)=0 \\
\partial \delta_{t+n-1}(i)+\pi_{t+n-1}(i, 1) \partial A_{t+n}(i)=0
\end{gathered}
$$

We write the value function under complete markets as

$$
\begin{aligned}
& V_{t}\left(\Delta_{t+n-1}(i), \delta_{t+n-1}(i)\right)=\left\{\omega\left(h_{t}\right)^{\gamma} C_{t}^{1-\gamma}+\sum_{s=1}^{n-1} \beta^{s} \sum_{i=2}^{3} \pi_{t}^{s}\left(h_{t}, i\right) \omega(i)^{\gamma} C_{t+s}(i)^{1-\gamma}\right. \\
& +\sum_{s=1}^{n} \beta^{s} \sum_{i=2}^{3} \pi_{t}^{s-1}\left(h_{t}, i\right) \pi_{t+s-1}(i, 1) \omega(1)^{\gamma}\left(\delta_{t+s-1}(i)+A_{t+s}(i)\right)^{1-\gamma} \\
& +\beta^{n} \sum_{i=2}^{3}\left[\pi_{t}^{n-1}\left(h_{t}, i\right) \pi_{t+n-1}(i, 2) V_{t+n}\left(2, \Delta_{t+n-1}(i)+A_{t+n}(i)+Y_{t+n}(2)-M_{t+n}(2)\right)^{1-\gamma}\right. \\
& \left.\left.+\pi_{t}^{n-1}\left(h_{t}, i\right) \pi_{t+n-1}(i, 3) V_{t+n}\left(3, A_{t+n}(i)+Y_{t+n}(3)-M_{t+n}(3)\right)^{1-\gamma}\right]\right\}^{1 /(1-\gamma)}
\end{aligned}
$$


Iterating forward on the first-order conditions (A9),

$$
\begin{aligned}
& \left(\frac{\omega\left(h_{t}\right)}{c_{t}\left(h_{t}\right)}\right)^{\gamma /(1-\gamma)} V_{t}^{*-\gamma}=(\beta R)^{n} \omega(1)^{\gamma}\left(\delta_{t+n-1}^{*}(i)+A_{t+n}^{*}(i)\right)^{-\gamma} \\
& =(\beta R)^{n}\left(\frac{\omega(2)}{c_{t+n}(2)}\right)^{\gamma /(1-\gamma)} V_{t+n}\left(2, \Delta_{t+n-1}^{*}(i)+A_{t+n}^{*}(i)+Y_{t+n}(2)-M_{t+n}(2)\right)^{-\gamma} \\
& =(\beta R)^{n}\left(\frac{\omega(3)}{c_{t+n}(3)}\right)^{\gamma /(1-\gamma)} V_{t+n}\left(3, A_{t+n}^{*}(i)+Y_{t+n}(3)-M_{t+n}(3)\right)^{-\gamma} .
\end{aligned}
$$

Taking the partial derivative of equation (A14) with respect to $\Delta_{t+n-1}(i)$,

$$
\begin{aligned}
& \frac{\partial V_{t}\left(\Delta_{t+n-1}(i), \delta_{t+n-1}(i)\right)}{\partial \Delta_{t+n-1}(i)}=\beta^{n} \pi_{t}^{n-1}\left(h_{t}, i\right) \pi_{t+n-1}(i, 2) V_{t}^{\gamma} \\
& \times\left[-\pi_{t+n-1}(i, 1) \omega(1)^{\gamma}\left(\delta_{t+n-1}(i)+A_{t+n}(i)\right)^{-\gamma}\right. \\
& +\left(1-\pi_{t+n-1}(i, 2)\right)\left(\frac{\omega(2)}{c_{t+n}(2)}\right)^{\gamma /(1-\gamma)} V_{t+n}\left(2, \Delta_{t+n-1}(i)+A_{t+n}(i)+Y_{t+n}(2)-M_{t+n}(2)\right)^{-\gamma} \\
& \left.-\pi_{t+n-1}(i, 3)\left(\frac{\omega(3)}{c_{t+n}(3)}\right)^{\gamma /(1-\gamma)} V_{t+n}\left(3, A_{t+n}(i)+Y_{t+n}(3)-M_{t+n}(3)\right)^{-\gamma}\right] .
\end{aligned}
$$

Evaluating at the optimal policy,

$$
\frac{\partial V_{t}\left(\Delta_{t+n-1}^{*}(i), \delta_{t+n-1}^{*}(i)\right)}{\partial \Delta_{t+n-1}(i)}=0 .
$$

Similarly, the first partial derivative of the value function with respect to mortality delta, evaluated at the optimal policy, is

$$
\frac{\partial V_{t}\left(\Delta_{t+n-1}^{*}(i), \delta_{t+n-1}^{*}(i)\right)}{\partial \delta_{t+n-1}(i)}=0 .
$$

Taking the partial derivative of equation (A16) with respect to $\Delta_{t+n-1}(i)$ and evaluating 
at the optimal policy,

$$
\begin{aligned}
& \frac{\partial^{2} V_{t}\left(\Delta_{t+n-1}^{*}(i), \delta_{t+n-1}^{*}(i)\right)}{\partial \Delta_{t+n-1}(i)^{2}}=-\gamma \beta^{n} \pi_{t}^{n-1}\left(h_{t}, i\right) \pi_{t+n-1}(i, 2)^{2} V_{t}^{* \gamma} \\
& \times\left[\pi_{t+n-1}(i, 1) \omega(1)^{\gamma}\left(\delta_{t+n-1}^{*}(i)+A_{t+n}^{*}(i)\right)^{-1-\gamma}\right. \\
& +\frac{\left(1-\pi_{t+n-1}(i, 2)\right)^{2}}{\pi_{t+n-1}(i, 2)}\left(\frac{\omega(2)}{c_{t+n}(2)}\right)^{2 \gamma /(1-\gamma)} V_{t+n}\left(2, \Delta_{t+n-1}^{*}(i)+A_{t+n}^{*}(i)+Y_{t+n}(2)-M_{t+n}(2)\right)^{-1-\gamma} \\
& \left.+\pi_{t+n-1}(i, 3)\left(\frac{\omega(3)}{c_{t+n}(3)}\right)^{2 \gamma /(1-\gamma)} V_{t+n}\left(3, A_{t+n}^{*}(i)+Y_{t+n}(3)-M_{t+n}(3)\right)^{-1-\gamma}\right]
\end{aligned}
$$

Substituting the first-order conditions (A15),

$$
\begin{aligned}
& \frac{\partial^{2} V_{t}\left(\Delta_{t+n-1}^{*}(i), \delta_{t+n-1}^{*}(i)\right)}{\partial \Delta_{t+n-1}(i)^{2}}=-\frac{\gamma \pi_{t}^{n-1}\left(h_{t}, i\right) \pi_{t+n-1}(i, 2)^{2}}{\beta^{n / \gamma} R^{n(1+1 / \gamma)} V_{t}^{*}}\left(\frac{\omega\left(h_{t}\right)}{c_{t}\left(h_{t}\right)}\right)^{(1+\gamma) /(1-\gamma)} \\
& \times\left[\frac{\pi_{t+n-1}(i, 1)}{\omega(1)}+\frac{\left(1-\pi_{t+n-1}(i, 2)\right)^{2} c_{t+n}(2)}{\pi_{t+n-1}(i, 2) \omega(2)}+\frac{\pi_{t+n-1}(i, 3) c_{t+n}(3)}{\omega(3)}\right] .
\end{aligned}
$$

Similarly, the second partial derivative of the value function with respect to mortality delta, evaluated at the optimal policy, is

$$
\begin{aligned}
& \frac{\partial^{2} V_{t}\left(\Delta_{t+n-1}^{*}(i), \delta_{t+n-1}^{*}(i)\right)}{\partial \delta_{t+n-1}(i)^{2}}=-\frac{\gamma \pi_{t}^{n-1}\left(h_{t}, i\right) \pi_{t+n-1}(i, 1)^{2}}{\beta^{n / \gamma} R^{n(1+1 / \gamma)} V_{t}^{*}}\left(\frac{\omega\left(h_{t}\right)}{c_{t}\left(h_{t}\right)}\right)^{(1+\gamma) /(1-\gamma)} \\
& \times\left[\frac{\left(1-\pi_{t+n-1}(i, 1)\right)^{2}}{\pi_{t+n-1}(i, 1) \omega(1)}+\frac{\pi_{t+n-1}(i, 2) c_{t+n}(2)}{\omega(2)}+\frac{\pi_{t+n-1}(i, 3) c_{t+n}(3)}{\omega(3)}\right] .
\end{aligned}
$$

Finally, the cross-partial derivative of the value function with respect to health and mortality delta, evaluated at the optimal policy, is

$$
\begin{aligned}
& \frac{\partial^{2} V_{t}\left(\Delta_{t+n-1}^{*}(i), \delta_{t+n-1}^{*}(i)\right)}{\partial \Delta_{t+n-1}(i) \partial \delta_{t+n-1}(i)}=-\frac{\gamma \pi_{t}^{n-1}\left(h_{t}, i\right) \pi_{t+n-1}(i, 1) \pi_{t+n-1}(i, 2)}{\beta^{n / \gamma} R^{n(1+1 / \gamma)} V_{t}^{*}}\left(\frac{\omega\left(h_{t}\right)}{c_{t}\left(h_{t}\right)}\right)^{(1+\gamma) /(1-\gamma)} \\
& \times\left[-\frac{1-\pi_{t+n-1}(i, 1)}{\omega(1)}-\frac{\left(1-\pi_{t+n-1}(i, 2)\right) c_{t+n}(2)}{\omega(2)}+\frac{\pi_{t+n-1}(i, 3) c_{t+n}(3)}{\omega(3)}\right]
\end{aligned}
$$


Dividing by $V_{t}^{*}$ and substituting the value function (A10),

$$
\begin{aligned}
& \frac{\partial^{2} L_{t}\left(\Delta_{t+n-1}^{*}(i), \delta_{t+n-1}^{*}(i)\right)}{\partial \Delta_{t+n-1}(i)^{2}}=-\frac{\gamma \pi_{t}^{n-1}\left(h_{t}, i\right) \pi_{t+n-1}(i, 2)^{2} \omega\left(h_{t}\right)}{\beta^{n / \gamma} R^{n(1+1 / \gamma)} c_{t}\left(h_{t}\right) \widehat{W}_{t}^{2}} \\
& \times\left[\frac{\pi_{t+n-1}(i, 1)}{\omega(1)}+\frac{\left(1-\pi_{t+n-1}(i, 2)\right)^{2} c_{t+n}(2)}{\pi_{t+n-1}(i, 2) \omega(2)}+\frac{\pi_{t+n-1}(i, 3) c_{t+n}(3)}{\omega(3)}\right] . \\
& \frac{\partial^{2} L_{t}\left(\Delta_{t+n-1}^{*}(i), \delta_{t+n-1}^{*}(i)\right)}{\partial \delta_{t+n-1}(i)^{2}}=-\frac{\gamma \pi_{t}^{n-1}\left(h_{t}, i\right) \pi_{t+n-1}(i, 1)^{2} \omega\left(h_{t}\right)}{\beta^{n / \gamma} R^{n(1+1 / \gamma)} c_{t}\left(h_{t}\right) \widehat{W}_{t}^{2}} \\
& \times\left[\frac{\left(1-\pi_{t+n-1}(i, 1)\right)^{2}}{\pi_{t+n-1}(i, 1) \omega(1)}+\frac{\pi_{t+n-1}(i, 2) c_{t+n}(2)}{\omega(2)}+\frac{\pi_{t+n-1}(i, 3) c_{t+n}(3)}{\omega(3)}\right] . \\
& \frac{\partial^{2} L_{t}\left(\Delta_{t+n-1}^{*}(i), \delta_{t+n-1}^{*}(i)\right)}{\partial \Delta_{t+n-1}(i) \partial \delta_{t+n-1}(i)}=-\frac{\gamma \pi_{t}^{n-1}\left(h_{t}, i\right) \pi_{t+n-1}(i, 1) \pi_{t+n-1}(i, 2) \omega\left(h_{t}\right)}{\beta^{n / \gamma} R^{n(1+1 / \gamma)} c_{t}\left(h_{t}\right) \widehat{W}_{t}^{2}} \\
& \times\left[-\frac{1-\pi_{t+n-1}(i, 1)}{\omega(1)}-\frac{\left(1-\pi_{t+n-1}(i, 2)\right) c_{t+n}(2)}{\omega(2)}+\frac{\pi_{t+n-1}(i, 3) c_{t+n}(3)}{\omega(3)}\right] .
\end{aligned}
$$

\section{Appendix B. Health and Retirement Study}

The Health and Retirement Study is a panel survey designed to study the health and wealth dynamics of the elderly in the United States. The data consist of five cohorts: the Study of Assets and Health Dynamics among the Oldest Old (born before 1924), the Children of Depression (born 1924 to 1930), the initial HRS cohort (born 1931 to 1941), the War Baby (born 1942 to 1947), and the Early Baby Boomer (born 1948 to 1953). Many of the variables that we use are from the RAND HRS (Version I), which is produced by the RAND Center for the Study of Aging with funding from the National Institute on Aging and the Social Security Administration. Whenever necessary, we use variables from both the core and exit interviews to supplement the RAND HRS. The data consist of eight waves, covering every two years between 1992 and 2006.

The Health and Retirement Study continues to interview respondents that enter nursing homes. However, any respondent that enters a nursing home receives a zero sampling weight because these weights are based on the non-institutionalized population of the Current Population Survey. Therefore, the use of sampling weights would lead us to underestimate nursing 
home expenses, which account for a significant share of out-of-pocket health expenses for older households. Because nursing home expenses are important for this paper, we do not use sampling weights in any of our analysis.

Since wave 3, the survey asks bracketing questions to solicit a range of values for questions that initially receive a non-response. Based on the range of values implied by the bracketing questions, we use the following methodology to impute missing observations. For each missing observation, we calculate the minimum and maximum values that are implied by the responses to the bracketing questions. For each non-missing observation, we set the minimum and maximum values to be the valid response. We then estimate the mean and the standard deviation of the variable in question through interval regression, under the assumption of log-normality. Finally, we fill in each missing observation as the conditional mean of the distribution in the bracketed range.

\section{B.1 Out-of-Pocket Health Expenses}

Out-of-pocket health expenses from the RAND HRS are the total amount paid for hospitals, nursing homes, doctor visits, dentist visits, outpatient surgery, prescription drugs, home health care, and special facilities. Payments of health insurance premiums from the core interviews are the sum of premiums paid for Medicare/Medicaid HMO, private health insurance, long-term care insurance, and prescription drug coverage (i.e., Medicare Part D). We convert the premium reported at monthly, quarterly, semi-annual, or annual frequency to the total implied payment over the previous two years.

Since wave 3, out-of-pocket health expenses at the end of life are available through the exit interviews. Without end-of-life expenses, we would underestimate the true cost of poor health in old age, especially in the upper tail of the distribution (Marshall, McGarry, and Skinner, 2011). Out-of-pocket health expenses from the exit interviews are the total amount paid for hospitals, nursing homes, doctor visits, prescription drugs, home health care, other health services, other medical expenses, and other non-medical expenses. 
We measure out-of-pocket health expenses as the sum of out-of-pocket health expenses from the RAND HRS and payments of health insurance premiums from the core interviews. For the last core interview prior to death of the primary respondent, we also add out-of-pocket health expenses at the end of life from the exit interviews. We measure out-of-pocket health expenses at the household level as the sum of these expenses for both the male respondent and his wife, if married.

We estimate the life-cycle profile for out-of-pocket health expenses through a panel regression with household fixed effects. We model the logarithm of real out-of-pocket health expenses as a function of dummy variables for health and 65 or older, a quadratic polynomial in age, income, and the interaction of the dummy variables with age and income. The dummy variable for 65 or older allows for potential changes in household behavior when they become eligible for Social Security and Medicare. We use the estimated regression model, averaging the household fixed effects by cohort and ownership of supplementary health insurance and long-term care insurance, to predict out-of-pocket health expenses in the absence of these policies by cohort, age, and health.

\section{B.2 Income}

Income includes labor income, Social Security disability and supplemental security income, Social Security retirement income, and unemployment or workers compensation. Income excludes pension and annuity income and capital income. We calculate after-tax income by subtracting federal income tax liabilities, estimated through the NBER TAXSIM program (Version 9). We measure household income as the sum of income for both the male respondent and his wife, if married.

We estimate the life-cycle profile for income through a panel regression with household fixed effects. We model the logarithm of real after-tax income as a function of a dummy variable for 65 or older, a quadratic polynomial in age, and the interaction of the dummy variable with age. We use the estimated regression model, averaging the household fixed 
effects by cohort, to predict income by cohort and age.

\section{B.3 Life Insurance}

We measure the ownership and the face value of life insurance using the core interviews. Term-life insurance refers to individual and group policies that have only a death benefit. Whole-life insurance refers to policies that build cash value, from which the policyholder can borrow or receive cash upon surrender of the policy. In waves 1 through 3 , we measure the total face value of all policies as the sum of the face value of term- and whole-life insurance. In wave 4 , only the total face value of all policies, and not the breakdown between termand whole-life insurance, is available. In waves 5 through 8 , we measure the total face value of term-life insurance as the difference between the face value of all policies and whole-life insurance.

We estimate the life-cycle profile for the face value of life insurance through a panel regression with household fixed effects. We model the logarithm of the real face value of life insurance as a function of dummy variables for health and 65 or older, a quadratic polynomial in age, income, and the interaction of the dummy variables with age and income. We use the estimated regression model, averaging the household fixed effects by cohort, to predict the face value of life insurance by cohort, age, and health.

\section{B.4 Annuities including Private Pensions}

We define ownership of annuities including private pensions as either participation in a defined-benefit plan at the present employer or positive reported pension and annuity income. We estimate the life-cycle profile for pension and annuity income through a panel regression with household fixed effects. We model the logarithm of real pension and annuity income as a function of dummy variables for health and 65 or older, a quadratic polynomial in age, income, and the interaction of the dummy variables with age and income. We use the estimated regression model, averaging the household fixed effects by cohort, to predict 
pension and annuity income by cohort, age, and health.

\section{B.5 Net Worth}

Household assets include checking, savings, and money market accounts; CD, government savings bonds, and T-bills; bonds and bond funds; IRA and Keogh accounts; businesses; stocks, mutual funds, and investment trusts; and primary and secondary residence. Household liabilities include all mortgages for primary and secondary residence, other home loans for primary residence, and other debt. Net worth is the value of assets minus the value of liabilities.

We estimate the life-cycle profile for net worth through a panel regression with household fixed effects. We model the logarithm of real net worth as a function of dummy variables for health and 65 or older, a quadratic polynomial in age, income, and the interaction of the

dummy variables with age and income. We use the estimated regression model, averaging the household fixed effects by cohort, to predict net worth by cohort, age, and health. 


\section{References}

Ameriks, John, Andrew Caplin, Steven Laufer, and Stijn Van Nieuwerburgh. 2011. "The Joy of Giving or Assisted Living? Using Strategic Surveys to Separate Bequest and Precautionary Motives." Journal of Finance 66 (2):519-561.

Barsky, Robert B., F. Thomas Juster, Miles S. Kimball, and Matthew D. Shapiro. 1997. "Preference Parameters and Behavioral Heterogeneity: An Experimental Approach in the Health and Retirement Study." Quarterly Journal of Economics 112 (2):537-579.

Bernheim, B. Douglas. 1991. "How Strong Are Bequest Motives? Evidence Based on Estimates of the Demand for Life Insurance and Annuities." Journal of Political Economy $99(5): 899-927$.

Brown, Jeffrey R. 2001. "Private Pensions, Mortality Risk, and the Decision to Annuitize." Journal of Public Economics 82 (1):29-62.

Bundorf, M. Kate, Jonathan D. Levin, and Neale Mahoney. 2008. "Pricing and Welfare in Health Plan Choice." NBER Working Paper No. 14153.

Calvet, Laurent E., John Y. Campbell, and Paolo Sodini. 2007. "Down or Out: Assessing the Welfare Costs of Household Investment Mistakes." Journal of Political Economy $115(5): 707-747$.

Cawley, John and Tomas Philipson. 1999. "An Empirical Examination of Information Barriers to Trade in Insurance." American Economic Review 89 (4):827-846.

Cochrane, John H. 1989. "The Sensitivity of Tests of the Intertemporal Allocation of Consumption to Near-Rational Alternatives." American Economic Review 79 (3):319-337.

—. 1995. "Time-Consistent Health Insurance." Journal of Political Economy 103 (3):445-473. 
de Meza, David and David C. Webb. 2001. "Advantageous Selection in Insurance Markets." RAND Journal of Economics 32 (2):249-262.

De Nardi, Mariacristina, Eric French, and John Bailey Jones. 2010. "Why Do the Elderly Save? The Role of Medical Expenses." Journal of Political Economy 118 (1):39-75.

Einav, Liran, Amy Finkelstein, and Mark R. Cullen. 2010. "Estimating Welfare in Insurance Markets Using Variation in Prices." Quarterly Journal of Economics 125 (3):877-921.

Einav, Liran, Amy Finkelstein, and Paul Schrimpf. 2010. "Optimal Mandates and the Welfare Cost of Asymmetric Information: Evidence from the U.K. Annuity Market." Econometrica 78 (3):1031-1092.

Fang, Hanming, Michael P. Keane, and Dan Silverman. 2008. "Sources of Advantageous Selection: Evidence from the Medigap Insurance Market." Journal of Political Economy $116(2): 303-350$.

Fang, Hanming and Edward Kung. 2010. "Why Do Life Insurance Policyholders Lapse? The Roles of Income, Health and Bequest Motive Shocks." Working paper, University of Pennsylvania.

Finkelstein, Amy, Erzo F. P. Luttmer, and Matthew J. Notowidigdo. 2008. "What Good Is Wealth without Health? The Effect of Health on the Marginal Utility of Consumption." NBER Working Paper No. 14089.

Finkelstein, Amy and Kathleen McGarry. 2006. "Multiple Dimensions of Private Information: Evidence from the Long-Term Care Insurance Market." American Economic Review $96(4): 938-958$.

Finkelstein, Amy and James Poterba. 2004. "Adverse Selection in Insurance Markets: Policyholder Evidence from the U.K. Annuity Market." Journal of Political Economy $112(1): 183-208$. 
Inkmann, Joachim, Paula Lopes, and Alexander Michaelides. 2011. "How Deep Is the Annuity Market Participation Puzzle?" Review of Financial Studies 24 (1):279-319.

Inkmann, Joachim and Alexander Michaelides. 2011. "Can the Life Insurance Market Provide Evidence for a Bequest Motive?" Working paper, University of Melbourne.

Marshall, Samuel, Kathleen M. McGarry, and Jonathan S. Skinner. 2011. "The Risk of Outof-Pocket Health Care Expenditure at the End of Life." In Explorations in the Economics of Aging, edited by David A. Wise, chap. 3. Chicago: The University of Chicago Press, $101-128$.

Milevsky, Moshe A. and David S. Promislow. 2001. "Mortality Derivatives and the Option to Annuitise." Insurance: Mathematics and Economics 29 (3):299-318.

Mitchell, Olivia S., James M. Poterba, Mark J. Warshawsky, and Jeffrey R. Brown. 1999. "New Evidence on the Money's Worth of Individual Annuities." American Economic Review 89 (5):1299-1318.

Viscusi, W. Kip and William N. Evans. 1990. "Utility Functions that Depend on Health Status: Estimates and Economic Implications." American Economic Review 80 (3):353374.

Yogo, Motohiro. 2011. "Portfolio Choice in Retirement: Health Risk and the Demand for Annuities, Housing, and Risky Assets." NBER Working Paper No. 15307. 
Table 1: Life Insurance and Annuity Products Offered by TIAA-CREF

This table lists the life insurance and annuity products offered by TIAA-CREF, a financial services company based in New York, as of December 2010.

\begin{tabular}{lll}
\hline Name of product & Term & Income deferrable \\
\hline Panel A: Life insurance products & \\
Annual Renewable Term & 1 year & \\
Level Term & $10,15,20$, or 30 years & \\
Intelligent Life Universal & Life & \\
\hline Panel B: Annuity products & & \\
Single Premium Immediate & Life & 14 months-90th birthday \\
Investment Horizon & Life & \\
\hline
\end{tabular}


Table 2: Predicting Future Mortality with Observed Health Problems

This table reports an estimate of a probit model for predicting death within two years from the present interview. The explanatory variables include dummy variables for doctordiagnosed health problems, age, the interaction of the health problems with age, and cohort dummies. The omitted cohort is those born prior to 1911. The table reports the marginal effects on the mortality rate (in percentage points) with heteroskedasticity-robust $t$-statistics in parentheses. The sample consists of male respondents aged 51 and older in the Health and Retirement Study for the period 1992 to 2006.

\begin{tabular}{|c|c|c|}
\hline Explanatory variable & $\begin{array}{r}\text { Marginal } \\
\text { effect }\end{array}$ & $t$-statistic \\
\hline \multicolumn{3}{|c|}{ Doctor-diagnosed health problems: } \\
\hline High blood pressure & 1.66 & $(3.52)$ \\
\hline Diabetes & 5.66 & $(6.41)$ \\
\hline Cancer & 13.62 & $(8.61)$ \\
\hline Lung disease & 8.21 & $(6.17)$ \\
\hline Heart problems & 2.60 & $(4.18)$ \\
\hline Stroke & 5.57 & $(4.40)$ \\
\hline$($ Age -51$) / 10$ & 3.26 & $(12.71)$ \\
\hline$\times$ High blood pressure & -0.44 & $(-2.31)$ \\
\hline$\times$ Diabetes & -0.72 & $(-3.07)$ \\
\hline$\times$ Cancer & -1.79 & $(-7.25)$ \\
\hline$\times$ Lung disease & -0.28 & $(-1.05)$ \\
\hline$\times$ Heart problems & 0.04 & $(0.18)$ \\
\hline$\times$ Stroke & -0.32 & $(-1.17)$ \\
\hline \multicolumn{3}{|l|}{ Birth cohort: } \\
\hline 1911-1915 & -1.69 & $(-5.23)$ \\
\hline $1916-1920$ & -2.39 & $(-8.16)$ \\
\hline $1921-1925$ & -3.32 & $(-12.17)$ \\
\hline $1926-1930$ & -3.58 & $(-11.69)$ \\
\hline $1931-1935$ & -3.74 & $(-8.79)$ \\
\hline $1936-1940$ & -4.08 & $(-8.37)$ \\
\hline $1941-1945$ & -3.46 & $(-8.33)$ \\
\hline $1946-1950$ & -3.51 & $(-9.47)$ \\
\hline $1951-1955$ & -3.03 & $(-4.97)$ \\
\hline \multicolumn{3}{|l|}{ Correctly predicted (\%): } \\
\hline Both outcomes & 92.87 & \\
\hline Dead only & 55.13 & \\
\hline Alive only & 93.01 & \\
\hline Observations & 43,452 & \\
\hline
\end{tabular}


Table 3: Health Problems, Health Care Utilization, and Health Insurance Coverage Panel A reports the percentage of individuals who have ever had doctor-diagnosed health problems or have some difficulty with activities of daily living at the time of interview. Panel B reports the percentage of individuals who have used health care in the two years prior to the interview. Panel $\mathrm{C}$ reports the percentage of individuals who have health insurance at the time of interview. Panel D reports the percentage of individuals who own life insurance or annuities including private pensions at the time of interview. It also reports the median of total face value conditional on ownership, deflated by the consumer price index to 2005 dollars. Term-life insurance refers to individual and group policies that have only a death benefit. Whole-life insurance refers to policies that build cash value, from which the policyholder can borrow or receive cash upon surrender of the policy. Supplementary health insurance includes Medigap insurance and refers to any coverage that is not government, employer-provided, or long-term care insurance. The sample consists of male respondents aged 51 and older in the Health and Retirement Study for the period 1992 to 2006.

\begin{tabular}{|c|c|c|c|c|c|c|}
\hline \multirow{2}{*}{$\begin{array}{l}\text { Age } \\
\text { Health }\end{array}$} & \multicolumn{2}{|c|}{$51-66$} & \multicolumn{2}{|c|}{$67-82$} & \multicolumn{2}{|c|}{$83-$} \\
\hline & Poor & Good & Poor & Good & Poor & Good \\
\hline \multicolumn{7}{|l|}{ Panel A: Health problems (\%) } \\
\hline \multicolumn{7}{|l|}{ Doctor-diagnosed health problems: } \\
\hline High blood pressure & 59 & 32 & 65 & 46 & 57 & 44 \\
\hline Diabetes & 22 & 9 & 34 & 14 & 20 & 14 \\
\hline Cancer & 9 & 4 & 30 & 12 & 28 & 20 \\
\hline Lung disease & 10 & 4 & 21 & 7 & 20 & 7 \\
\hline Heart problems & 28 & 11 & 56 & 26 & 77 & 31 \\
\hline Stroke & 7 & 3 & 21 & 6 & 33 & 11 \\
\hline \multicolumn{7}{|l|}{ Some difficulty with } \\
\hline Bathing & 5 & 1 & 10 & 4 & 27 & 15 \\
\hline Dressing & 9 & 4 & 14 & 8 & 30 & 18 \\
\hline Eating & 2 & 1 & 5 & 2 & 16 & 7 \\
\hline \multicolumn{7}{|l|}{ Panel B: Health care utilization (\%) } \\
\hline Monthly doctor visits & 11 & 4 & 17 & 8 & 21 & 12 \\
\hline Hospital stay & 27 & 14 & 43 & 26 & 54 & 37 \\
\hline Outpatient surgery & 21 & 17 & 26 & 21 & 24 & 21 \\
\hline Nursing home stay & 1 & 0 & 4 & 2 & 19 & 8 \\
\hline Home health care & 4 & 2 & 12 & 6 & 24 & 13 \\
\hline Special facilities and services & 7 & 4 & 10 & 6 & 15 & 11 \\
\hline Prescription drugs & 79 & 52 & 94 & 76 & 97 & 80 \\
\hline \multicolumn{7}{|l|}{ Panel C: Health insurance (\%) } \\
\hline Medicare & 22 & 17 & 98 & 97 & 99 & 98 \\
\hline Medicaid & 3 & 2 & 3 & 5 & 5 & 7 \\
\hline Employer-provided health insurance & 58 & 63 & 36 & 32 & 30 & 26 \\
\hline Supplementary health insurance & 10 & 11 & 33 & 32 & 38 & 38 \\
\hline Long-term care insurance & 7 & 7 & 12 & 13 & 10 & 9 \\
\hline \multicolumn{7}{|c|}{$\begin{array}{l}\text { Panel D: Life insurance, annuities including private pensions, and net worth (thousands of } 2005 \text { dollars) } \\
\text { Ownership rate }(\%):\end{array}$} \\
\hline All life insurance & 78 & 80 & 71 & 71 & 59 & 57 \\
\hline Term-life insurance & 62 & 65 & 50 & 51 & 38 & 38 \\
\hline Whole-life insurance & 29 & 33 & 30 & 28 & 23 & 19 \\
\hline Annuities including private pensions & 40 & 45 & 56 & 54 & 52 & 53 \\
\hline Annuities excluding private pensions & 1 & 1 & 4 & 4 & 6 & 6 \\
\hline \multicolumn{7}{|l|}{ Median face value conditional on ownership: } \\
\hline All life insurance & 57 & 72 & 18 & 20 & 10 & 10 \\
\hline Term-life insurance & 50 & 67 & 12 & 14 & 7 & 7 \\
\hline Whole-life insurance & 35 & 40 & 20 & 20 & 11 & 11 \\
\hline Net worth excluding life insurance and annuities & 120 & 161 & 186 & 187 & 170 & 153 \\
\hline
\end{tabular}


Table 4: Health Distribution, Life Expectancy, and Out-of-Pocket Health Expenses Panel A reports the health distribution at each age for a population of individuals who are in good health at age 51. Panel B reports the remaining life expectancy by age and health. Panel C reports annual out-of-pocket health expenses by age and health in thousands of 2005 dollars. Panel D reports annual income by age in thousands of 2005 dollars. Panel E reports the present value of future income in excess of out-of-pocket health expenses by age and health in thousands of 2005 dollars. The reported estimates are for male respondents in good health at age 51, born 1936 to 1940 in the Health and Retirement Study.

\begin{tabular}{|c|c|c|c|c|c|c|c|}
\hline \multirow[t]{2}{*}{ Health } & \multicolumn{7}{|c|}{ Age } \\
\hline & 51 & 59 & 67 & 75 & 83 & 91 & 99 \\
\hline \multicolumn{8}{|c|}{ Panel A: Health distribution (\%) } \\
\hline Dead & 0 & 15 & 30 & 45 & 62 & 83 & 97 \\
\hline Poor & 0 & 22 & 18 & 16 & 14 & 9 & 2 \\
\hline Good & 100 & 63 & 52 & 39 & 23 & 8 & 1 \\
\hline \multicolumn{8}{|c|}{ Panel B: Life expectancy (years) } \\
\hline Poor & 24 & 20 & 15 & 11 & 8 & 5 & 4 \\
\hline Good & 26 & 23 & 19 & 14 & 10 & 7 & 4 \\
\hline Mean & 26 & 22 & 18 & 13 & 9 & 6 & 4 \\
\hline \multicolumn{8}{|c|}{$\begin{array}{l}\text { Panel C: Out-of-pocket health expenses } \\
\text { (thousands of } 2005 \text { dollars per year) }\end{array}$} \\
\hline Poor & 2 & 5 & 8 & 13 & 21 & 38 & 70 \\
\hline Good & 0 & 1 & 3 & 5 & 7 & 11 & 14 \\
\hline Mean & 0 & 2 & 4 & 7 & 13 & 25 & 54 \\
\hline \multicolumn{8}{|c|}{ Panel D: Income (thousands of 2005 dollars per year) } \\
\hline Mean & 51 & 38 & 26 & 21 & 18 & 16 & 14 \\
\hline \multicolumn{8}{|c|}{$\begin{array}{l}\text { Panel E: Present value of future disposable income } \\
\text { (thousands of } 2005 \text { dollars) }\end{array}$} \\
\hline Poor & 428 & 232 & 107 & 18 & -42 & -78 & -96 \\
\hline Good & 467 & 270 & 135 & 31 & -49 & -106 & -135 \\
\hline Mean & 467 & 260 & 128 & 27 & -46 & -91 & -107 \\
\hline
\end{tabular}


Table 5: Determinants of Health and Mortality Delta

The explanatory variables in the first specification include dummy variables for poor health and 65 or older, a quadratic polynomial in age, the interaction of the dummy variables with age, and cohort dummies. The omitted cohort is those born prior to 1911. Additional explanatory variables in the second specification include dummy variables for marital status, living children, education, and self-reported general health status. The omitted categories are no-high school education and good selfreported health status. The table reports the regression coefficients with heteroskedasticity-robust $t$-statistics in parentheses. The sample consists of male respondents aged 51 and older in the Health and Retirement Study for the period 1992 to 2006.

\begin{tabular}{|c|c|c|c|c|c|c|c|c|}
\hline \multirow[t]{2}{*}{ Explanatory variable } & \multicolumn{4}{|c|}{ Health delta } & \multicolumn{4}{|c|}{ Mortality delta } \\
\hline & \multicolumn{2}{|c|}{$(1)$} & \multicolumn{2}{|c|}{$(2)$} & \multicolumn{2}{|c|}{$(3)$} & \multicolumn{2}{|c|}{$(4)$} \\
\hline Poor health & 1.13 & $\overline{(3.13)}$ & 0.91 & $\overline{(2.49)}$ & -15.50 & $(-3.42)$ & -1.98 & $(-0.44)$ \\
\hline 65 or older & -10.46 & $(-4.34)$ & -4.40 & $(-1.79)$ & -150.00 & $(-11.28)$ & -100.00 & $(-7.49)$ \\
\hline Married & & & -0.13 & $(-0.29)$ & & & 42.60 & $(7.69)$ \\
\hline Has living children & & & 0.98 & $(1.69)$ & & & 33.49 & $(4.27)$ \\
\hline \multicolumn{9}{|l|}{ Education: } \\
\hline High school graduate & & & -0.39 & $(-1.02)$ & & & 21.09 & $(5.54)$ \\
\hline College graduate & & & 3.27 & $(5.68)$ & & & 126.00 & $(20.08)$ \\
\hline \multicolumn{9}{|l|}{ Self-reported health status: } \\
\hline Poor & & & 1.16 & $(2.15)$ & & & 39.46 & $(5.65)$ \\
\hline Fair & & & 0.13 & $(0.28)$ & & & 19.60 & $(3.51)$ \\
\hline Very good & & & 0.02 & $(0.04)$ & & & -15.05 & $(-2.51)$ \\
\hline Excellent & & & 1.90 & $(2.68)$ & & & -11.77 & $(-1.73)$ \\
\hline$($ Age -51$) / 10$ & -1.79 & $(-1.28)$ & 17.02 & $(8.59)$ & -23.93 & $(-1.67)$ & 151.59 & $(8.98)$ \\
\hline$\times$ Poor health & -2.68 & $(-3.79)$ & -4.35 & $(-6.14)$ & -1.69 & $(-0.31)$ & -19.97 & $(-3.71)$ \\
\hline$\times 65$ or older & -3.16 & $(-1.34)$ & -11.34 & $(-4.64)$ & 44.85 & $(2.64)$ & -17.43 & $(-1.01)$ \\
\hline × Married & & & -2.82 & $(-3.77)$ & & & -40.07 & $(-6.85)$ \\
\hline$\times$ Has living children & & & -5.02 & $(-4.57)$ & & & -40.17 & $(-4.65)$ \\
\hline$\times$ High school graduate & & & -7.60 & $(-12.23)$ & & & -49.33 & $(-11.62)$ \\
\hline$\times$ College graduate & & & -19.95 & $(-18.75)$ & & & -170.00 & $(-22.17)$ \\
\hline$\times$ Poor & & & -3.20 & $(-2.78)$ & & & -38.39 & $(-4.31)$ \\
\hline$\times$ Fair & & & -1.93 & $(-2.19)$ & & & -21.64 & $(-3.25)$ \\
\hline$\times$ Very good & & & 3.73 & $(4.29)$ & & & 28.94 & $(4.43)$ \\
\hline$\times$ Excellent & & & 4.73 & $(4.36)$ & & & 39.30 & $(5.31)$ \\
\hline$(\text { Age }-51)^{2} / 100$ & -6.44 & $(-5.71)$ & -12.38 & $(-10.32)$ & -38.65 & $(-4.00)$ & -83.69 & $(-8.49)$ \\
\hline$\times$ Poor health & 0.61 & $(3.24)$ & 1.14 & $(6.04)$ & 1.53 & $(1.20)$ & 5.81 & $(4.50)$ \\
\hline$\times 65$ or older & 8.04 & $(6.82)$ & 11.11 & $(9.32)$ & 38.79 & $(3.97)$ & 60.56 & $(6.22)$ \\
\hline$\times$ Married & & & 0.81 & $(4.24)$ & & & 7.98 & $(6.05)$ \\
\hline$\times$ Has living children & & & 1.38 & $(4.88)$ & & & 8.79 & $(4.48)$ \\
\hline$\times$ High school graduate & & & 1.93 & (11.93) & & & 11.45 & $(11.47)$ \\
\hline$\times$ College graduate & & & 4.39 & $(15.50)$ & & & 33.97 & $(18.46)$ \\
\hline$\times$ Poor & & & 0.94 & $(3.02)$ & & & 8.21 & $(3.73)$ \\
\hline$\times$ Fair & & & 0.63 & $(2.68)$ & & & 4.89 & $(3.02)$ \\
\hline$\times$ Very good & & & -1.04 & $(-4.64)$ & & & -7.01 & $(-4.64)$ \\
\hline$\times$ Excellent & & & -1.41 & $(-5.21)$ & & & -9.95 & $(-5.89)$ \\
\hline \multicolumn{9}{|l|}{ Birth cohort: } \\
\hline 1911-1915 & -0.70 & $(-1.27)$ & -0.79 & $(-1.49)$ & 0.25 & $(0.13)$ & -0.96 & $(-0.49)$ \\
\hline $1916-1920$ & -4.67 & $(-7.23)$ & -3.54 & $(-5.79)$ & -10.97 & $(-4.63)$ & -6.97 & $(-3.06)$ \\
\hline $1921-1925$ & -5.83 & $(-7.94)$ & -3.58 & $(-5.14)$ & -16.26 & $(-5.96)$ & -7.23 & $(-2.76)$ \\
\hline $1926-1930$ & -9.07 & $(-10.53)$ & -5.59 & $(-6.76)$ & -25.71 & $(-7.61)$ & -11.78 & $(-3.59)$ \\
\hline 1931-1935 & -7.00 & $(-7.41)$ & -3.63 & $(-4.00)$ & -19.33 & $(-4.85)$ & -4.81 & $(-1.24)$ \\
\hline $1936-1940$ & -6.56 & $(-6.55)$ & -2.48 & $(-2.57)$ & -6.43 & $(-1.43)$ & 9.93 & $(2.26)$ \\
\hline 1941-1945 & -6.51 & $(-6.36)$ & -2.22 & $(-2.23)$ & 15.17 & $(3.09)$ & 30.23 & $(6.23)$ \\
\hline 1946-1950 & -6.40 & $(-6.32)$ & -2.12 & $(-2.16)$ & 37.09 & (6.28) & 48.77 & $(8.40)$ \\
\hline 1951-1955 & -6.79 & $(-6.60)$ & -2.72 & $(-2.73)$ & 27.15 & $(3.25)$ & 43.84 & $(5.28)$ \\
\hline$R^{2}(\%)$ & 6.60 & & 13.00 & & 12.08 & & 15.83 & \\
\hline Observations & 32,778 & & 32,341 & & 32,778 & & 32,341 & \\
\hline
\end{tabular}


Table 6: Preference Parameters

The subjective discount factor is reported in annualized units. The value for relative risk aversion is based on a previous estimate in the Health and Retirement Study (Barsky et al., 1997). The utility weights for death and poor health are estimated by continuous-updating generalized method of moments with heteroskedasticity-robust standard errors in parentheses. The sample consists of male respondents aged 51 and older in the Health and Retirement Study for the period 1992 to 2006.

\begin{tabular}{llr}
\hline Parameter & Symbol & Value \\
\hline Subjective discount factor & $\beta$ & 0.96 \\
Relative risk aversion & $\gamma$ & 4 \\
Utility weight for death & $\omega(1)$ & 5.00 \\
& & $(0.13)$ \\
Utility weight for poor health & $\omega(2)$ & 0.84 \\
& & $(0.02)$ \\
Utility weight for good health & $\omega(3)$ & 1.00 \\
\hline
\end{tabular}


Table 7: Welfare Cost of Household Insurance Choice

This table reports the median welfare cost by age group, expressed as a percentage of total wealth. The welfare cost for each household is measured by the deviations of the observed health and mortality delta from the optimal health and mortality delta. The lifetime cost is based on the probability of future ownership of health and longevity products, implied by the probit model in Table 8. The sample consists of male respondents aged 51 and older in the Health and Retirement Study for the period 1992 to 2006.

\begin{tabular}{lrrrrrr}
\hline & \multicolumn{6}{c}{ Age } \\
\cline { 2 - 7 } & $51-58$ & $59-66$ & $67-74$ & $75-82$ & $83-90$ & $91-$ \\
\hline Panel A: Per-period welfare cost (\% & of total wealth) & & & \\
Total cost & 0.87 & 0.56 & 0.53 & 0.64 & 0.81 & 0.94 \\
& $(0.09)$ & $(0.05)$ & $(0.05)$ & $(0.09)$ & $(0.26)$ & $(1.10)$ \\
Cost due to health delta & 0.02 & 0.05 & 0.09 & 0.15 & 0.19 & 0.15 \\
& $(0.00)$ & $(0.00)$ & $(0.00)$ & $(0.01)$ & $(0.08)$ & $(1.01)$ \\
Cost due to mortality delta & 0.87 & 0.54 & 0.48 & 0.59 & 0.83 & 1.20 \\
& $(0.09)$ & $(0.05)$ & $(0.06)$ & $(0.13)$ & $(0.35)$ & $(1.41)$ \\
\hline Panel B: Lifetime welfare cost (\% of total wealth) & & & \\
Total cost & 28.49 & 22.52 & 12.98 & 5.24 & 2.89 & 2.14 \\
& $(0.51)$ & $(0.32)$ & $(0.29)$ & $(0.22)$ & $(0.38)$ & $(1.41)$ \\
Cost due to health delta & 0.77 & 0.69 & 0.65 & 0.62 & 0.53 & 0.30 \\
Cost due to mortality delta & $(0.18)$ & $(0.02)$ & $(0.02)$ & $(0.05)$ & $(0.18)$ & $(1.35)$ \\
& 29.61 & 24.01 & 14.36 & 6.00 & 3.53 & 2.92 \\
& $(0.50)$ & $(0.31)$ & $(0.27)$ & $(0.24)$ & $(0.48)$ & $(1.82)$ \\
\hline
\end{tabular}


Table 8: Predicting the Future Ownership of Health and Longevity Products

This table reports an estimate of a probit model for predicting ownership of a given type of policy at two years from the present interview. The explanatory variables include dummy variables for present policy owner, poor health, and 65 or older; a quadratic polynomial in age; the interaction of the dummy variables with age; and cohort dummies. The omitted cohort is those born prior to 1911. The table reports the marginal effects on the probability of ownership (in percentage points) with heteroskedasticity-robust $t$-statistics in parentheses. The sample consists of male respondents aged 51 and older in the Health and Retirement Study for the period 1992 to 2006.

\begin{tabular}{|c|c|c|c|c|c|c|c|c|c|c|}
\hline \multirow{2}{*}{$\begin{array}{l}\text { Explanatory variable } \\
\text { Present owner }\end{array}$} & \multicolumn{2}{|c|}{$\begin{array}{l}\text { Term-life } \\
\text { insurance }\end{array}$} & \multicolumn{2}{|c|}{$\begin{array}{l}\text { Whole-life } \\
\text { insurance }\end{array}$} & \multicolumn{2}{|c|}{$\begin{array}{l}\text { Annuities including } \\
\text { private pensions }\end{array}$} & \multicolumn{2}{|c|}{$\begin{array}{c}\text { Supplementary } \\
\text { health insurance }\end{array}$} & \multicolumn{2}{|c|}{$\begin{array}{c}\text { Long-term } \\
\text { care insurance }\end{array}$} \\
\hline & 46.36 & $(24.39)$ & 66.80 & $(38.66)$ & 53.19 & $(43.64)$ & 33.46 & $(15.28)$ & 23.84 & $\overline{(9.13)}$ \\
\hline Poor health & -2.39 & $(-1.05)$ & -1.23 & $(-0.62)$ & -5.78 & $(-3.55)$ & 3.38 & $(2.67)$ & -1.42 & $(-1.97)$ \\
\hline 65 or older & -11.83 & $(-1.42)$ & -26.47 & $(-3.44)$ & 2.85 & $(0.40)$ & 19.82 & $(4.98)$ & 1.80 & $(0.58)$ \\
\hline$($ Age -51$) / 10$ & 17.02 & $(2.43)$ & -10.46 & $(-1.73)$ & -23.87 & $(-5.05)$ & -21.56 & $(-6.33)$ & -1.57 & $(-0.75)$ \\
\hline$\times$ Present owner & 2.97 & $(1.03)$ & -2.01 & $(-0.74)$ & 10.83 & $(4.95)$ & 6.38 & $(3.99)$ & 9.90 & $(7.45)$ \\
\hline$\times$ Poor health & -0.04 & $(-0.01)$ & 0.03 & $(0.01)$ & 5.57 & $(2.36)$ & -0.29 & $(-0.19)$ & 0.82 & $(0.76)$ \\
\hline$\times 65$ or older & -4.35 & $(-0.45)$ & 29.90 & $(3.41)$ & 13.96 & $(1.81)$ & 3.84 & $(0.83)$ & 1.28 & $(0.37)$ \\
\hline$(\text { Age }-51)^{2} / 100$ & -12.95 & $(-2.77)$ & 3.51 & $(0.85)$ & 11.83 & $(3.81)$ & 19.02 & $(8.60)$ & 2.26 & $(1.61)$ \\
\hline$\times$ Present owner & -0.48 & $(-0.60)$ & -0.16 & $(-0.21)$ & -0.53 & $(-0.84)$ & -1.17 & $(-2.86)$ & -1.42 & $(-3.88)$ \\
\hline$\times$ Poor health & 0.25 & $(0.29)$ & 0.27 & $(0.34)$ & -1.21 & $(-1.70)$ & 0.26 & $(0.62)$ & 0.08 & $(0.25)$ \\
\hline$\times 65$ or older & 11.03 & $(2.29)$ & -9.00 & $(-2.09)$ & -11.70 & $(-3.48)$ & -14.81 & $(-6.43)$ & -2.46 & $(-1.61)$ \\
\hline \multicolumn{11}{|l|}{ Birth cohort: } \\
\hline 1911-1915 & 8.00 & $(2.11)$ & -9.47 & $(-3.55)$ & 2.70 & $(0.87)$ & 12.74 & $(5.09)$ & 2.06 & $(0.92)$ \\
\hline 1916-1920 & 14.23 & $(3.86)$ & -11.61 & $(-4.54)$ & 0.90 & $(0.27)$ & 13.97 & $(5.07)$ & 1.79 & $(0.76)$ \\
\hline $1921-1925$ & 17.76 & $(4.75)$ & -13.74 & $(-5.32)$ & -2.59 & $(-0.72)$ & 15.12 & $(5.11)$ & 4.92 & $(1.68)$ \\
\hline 1926-1930 & 20.17 & $(5.25)$ & -16.40 & $(-6.53)$ & -3.83 & $(-1.03)$ & 18.48 & $(5.76)$ & 5.72 & $(1.85)$ \\
\hline 1931-1935 & 25.27 & $(6.54)$ & -18.78 & $(-6.93)$ & -6.80 & $(-1.78)$ & 16.72 & $(5.49)$ & 5.91 & $(1.98)$ \\
\hline 1936-1940 & 28.79 & $(7.45)$ & -22.52 & $(-8.44)$ & -10.14 & $(-2.63)$ & 14.18 & $(4.80)$ & 6.47 & $(2.16)$ \\
\hline $1941-1945$ & 31.50 & $(9.66)$ & -20.74 & $(-9.92)$ & -11.95 & $(-3.08)$ & 9.26 & $(2.98)$ & 9.16 & $(2.42)$ \\
\hline 1946-1950 & 35.92 & (14.07) & -22.17 & $(-14.75)$ & -14.27 & $(-3.62)$ & 6.48 & $(1.97)$ & 10.81 & $(2.48)$ \\
\hline $1951-1955$ & 36.75 & (16.66) & -21.57 & $(-17.05)$ & -21.89 & $(-5.39)$ & -0.89 & $(-0.27)$ & 11.23 & $(2.29)$ \\
\hline \multicolumn{11}{|c|}{ Correctly predicted (\%): } \\
\hline Both outcomes & 75.68 & & 85.20 & & 81.82 & & 85.07 & & 92.17 & \\
\hline Owner only & 77.24 & & 74.62 & & 81.84 & & 60.66 & & 64.51 & \\
\hline Not owner only & 73.56 & & 89.52 & & 81.79 & & 89.84 & & 94.37 & \\
\hline Observations & 18,353 & & 18,651 & & 39,457 & & 38,031 & & 38,080 & \\
\hline
\end{tabular}


Table 9: Lifetime Welfare Cost under Alternative Assumptions

This table reports the median lifetime welfare cost by age group, expressed as a percentage of total wealth. The table reports the welfare cost under alternative assumptions including a bequest motive that is weaker or stronger than the estimated bequest motive and health and longevity products that are more expensive than actuarially fair. The sample consists of male respondents aged 51 and older in the Health and Retirement Study for the period 1992 to 2006.

\begin{tabular}{lcrrrrrr}
\hline Parameter & Value & \multicolumn{6}{c}{ Age } \\
\cline { 3 - 8 } & & $51-58$ & $59-66$ & $67-74$ & $75-82$ & $83-90$ & $91-$ \\
\hline Panel A: Per-period welfare cost (\% of total wealth) & & & & \\
Utility weight for death & 4.00 & 0.91 & 0.62 & 0.61 & 0.80 & 1.09 & 1.27 \\
& & $(0.10)$ & $(0.06)$ & $(0.04)$ & $(0.08)$ & $(0.22)$ & $(1.04)$ \\
& \multirow{2}{*}{0.00} & 0.89 & 0.56 & 0.50 & 0.61 & 0.64 & 0.67 \\
& & $(0.08)$ & $(0.05)$ & $(0.05)$ & $(0.10)$ & $(0.28)$ & $(1.15)$ \\
Discount rate on life insurance & $0 \%$ & 0.84 & 0.54 & 0.52 & 0.63 & 0.80 & 0.94 \\
& & $(0.08)$ & $(0.05)$ & $(0.05)$ & $(0.09)$ & $(0.26)$ & $(1.10)$ \\
Discount rate on annuities & $0 \%$ & 0.84 & 0.56 & 0.53 & 0.65 & 0.81 & 0.92 \\
& & $(0.08)$ & $(0.05)$ & $(0.05)$ & $(0.09)$ & $(0.26)$ & $(1.10)$ \\
Discount rate on supplementary & $0 \%$ & 0.87 & 0.56 & 0.53 & 0.64 & 0.81 & 0.94 \\
health insurance & & $(0.09)$ & $(0.05)$ & $(0.05)$ & $(0.09)$ & $(0.26)$ & $(1.10)$ \\
\hline Panel B: Lifetime welfare cost (\% of total wealth) & & & & & \\
Utility weight for death & 4.00 & 36.97 & 29.91 & 17.26 & 7.29 & 4.33 & 3.02 \\
& & $(0.49)$ & $(0.35)$ & $(0.32)$ & $(0.21)$ & $(0.34)$ & $(1.30)$ \\
& 6.00 & 24.15 & 18.47 & 10.64 & 4.37 & 2.28 & 1.64 \\
& & $(0.52)$ & $(0.29)$ & $(0.27)$ & $(0.23)$ & $(0.42)$ & $(1.48)$ \\
Discount rate on life insurance & $0 \%$ & 28.26 & 22.34 & 12.91 & 5.22 & 2.88 & 2.14 \\
& & $(0.51)$ & $(0.32)$ & $(0.28)$ & $(0.22)$ & $(0.38)$ & $(1.41)$ \\
Discount rate on annuities & $0 \%$ & 27.84 & 22.08 & 12.64 & 5.16 & 2.90 & 2.22 \\
& & $(0.51)$ & $(0.31)$ & $(0.28)$ & $(0.21)$ & $(0.38)$ & $(1.40)$ \\
Discount rate on supplementary & $0 \%$ & 28.49 & 22.52 & 12.98 & 5.24 & 2.89 & 2.14 \\
health insurance & & $(0.51)$ & $(0.32)$ & $(0.29)$ & $(0.22)$ & $(0.38)$ & $(1.40)$ \\
\hline
\end{tabular}


Table 10: An Optimal Portfolio of Health and Longevity Products

Panel A reports the optimal health and mortality delta by age, implied by a life-cycle model with the preference parameters in Table 6. Panel B reports a portfolio of short-term life insurance, deferred annuities, short-term health insurance, and bonds that replicates the optimal health and mortality delta. Short-term policies have maturity of two years, and the income payments from deferred annuities start at age 65. Panel $\mathrm{C}$ reports the cost of the optimal portfolio in thousands of 2005 dollars, averaged across the health distribution at the given age. The reported estimates are for male respondents in good health at age 51, born 1936 to 1940 in the Health and Retirement Study.

\begin{tabular}{lrrrrrrr}
\hline & \multicolumn{7}{c}{ Age } \\
\cline { 2 - 8 } & 51 & 59 & 67 & 75 & 83 & 91 & 99 \\
\hline Panel A: Optimal health and & mortality & delta & (thousands & of 2005 & dollars) \\
Health delta & 7 & -3 & -13 & -20 & -17 & 8 & 83 \\
Mortality delta & 188 & 15 & -78 & -132 & -167 & -188 & -185 \\
\hline Panel B: Optimal portfolio & (units) & & & & & & \\
Short-term life insurance & 188 & 34 & 0 & 0 & 0 & 0 & 0 \\
Deferred annuity & 0 & 3 & 11 & 23 & 40 & 65 & 95 \\
Short-term health insurance & 1.80 & 0.00 & 0.07 & 0.53 & 0.77 & 0.82 & 0.85 \\
Bond & 60 & 204 & 228 & 219 & 210 & 201 & 193 \\
\hline Panel C: Cost of the optimal portfolio & thousands & of 2005 & dollars) & \\
Short-term life insurance & 5 & 1 & 0 & 0 & 0 & 0 & 0 \\
Deferred annuity & 0 & 17 & 68 & 110 & 125 & 115 & 83 \\
Short-term health insurance & 2 & 0 & 0 & 3 & 9 & 22 & 44 \\
Bond & 58 & 196 & 219 & 210 & 202 & 193 & 185 \\
Total cost & 65 & 215 & 287 & 323 & 335 & 330 & 312 \\
\hline
\end{tabular}



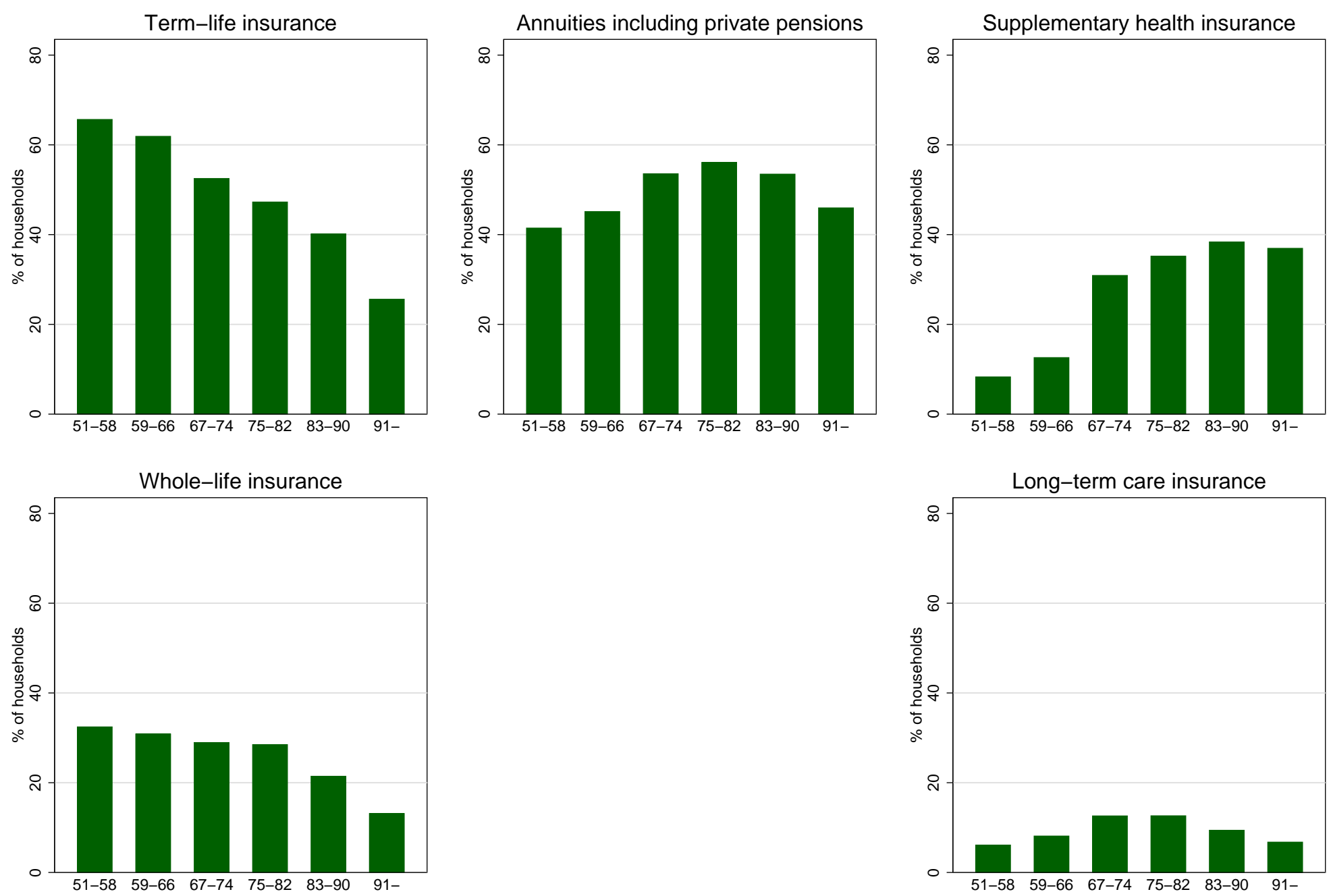

\section{Age}

Figure 1: Ownership Rates of Health and Longevity Products

Term-life insurance refers to individual and group policies that have only a death benefit. Whole-life insurance refers to policies that build cash value, from which the policyholder can borrow or receive cash upon surrender of the policy. Supplementary health insurance includes Medigap insurance and refers to any coverage that is not government, employer-provided, or long-term care insurance. The sample consists of male respondents aged 51 and older in the Health and Retirement Study for the period 1992 to 2006. 

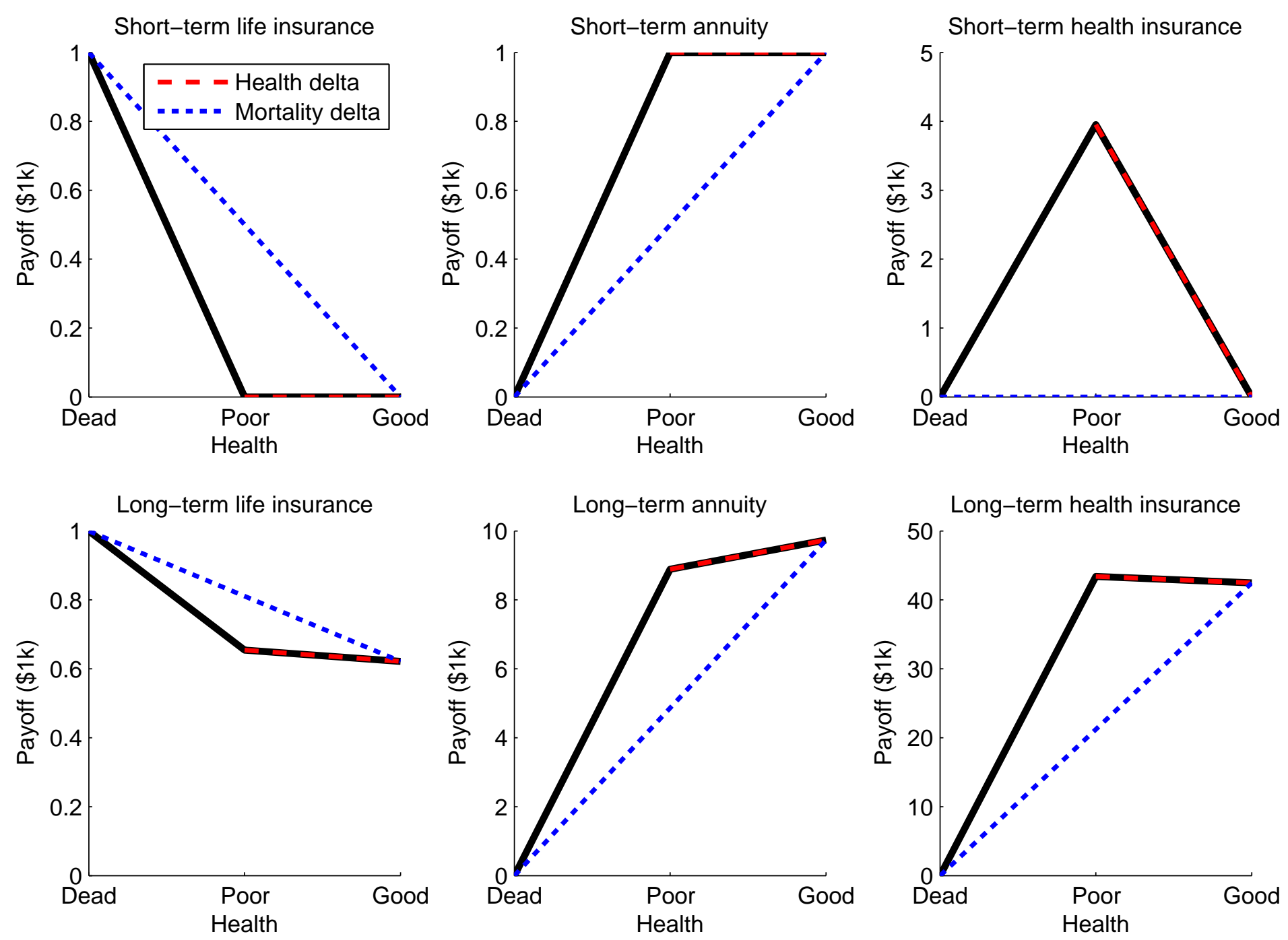

Figure 2: Health and Mortality Delta for Health and Longevity Products

This figure reports the health and mortality delta for life insurance, annuities, and health insurance. The solid line represents the payoff of each policy for the three possible health states in two years, reported in thousands of 2005 dollars. Health delta is minus the slope of the dashed line, normalizing the horizontal distance between good and poor health as one. Mortality delta is minus two times the slope of the dotted line, normalizing the horizontal distance between good health and death as two. Short-term policies have maturity of two years, while long-term policies mature at death. The reported estimates are for male respondents at age 51, born 1936 to 1940 in the Health and Retirement Study. 

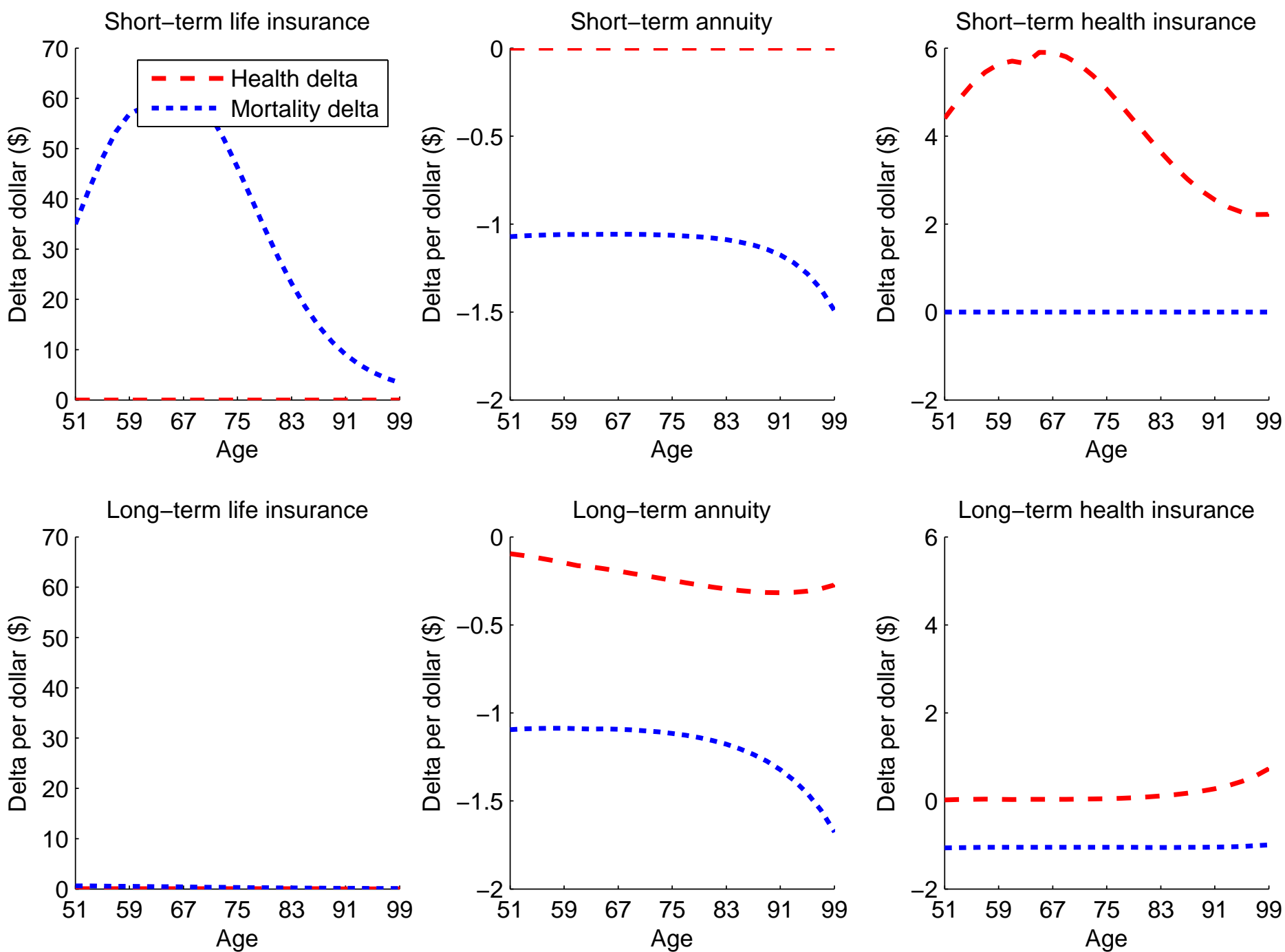

Figure 3: Health and Mortality Delta for Health and Longevity Products over the Life Cycle

This figure reports the health and mortality delta per dollar investment for life insurance, annuities, and health insurance. Short-term policies have maturity of two years, while long-term policies mature at death. The reported estimates are for male respondents in good health at the given age, born 1936 to 1940 in the Health and Retirement Study. 

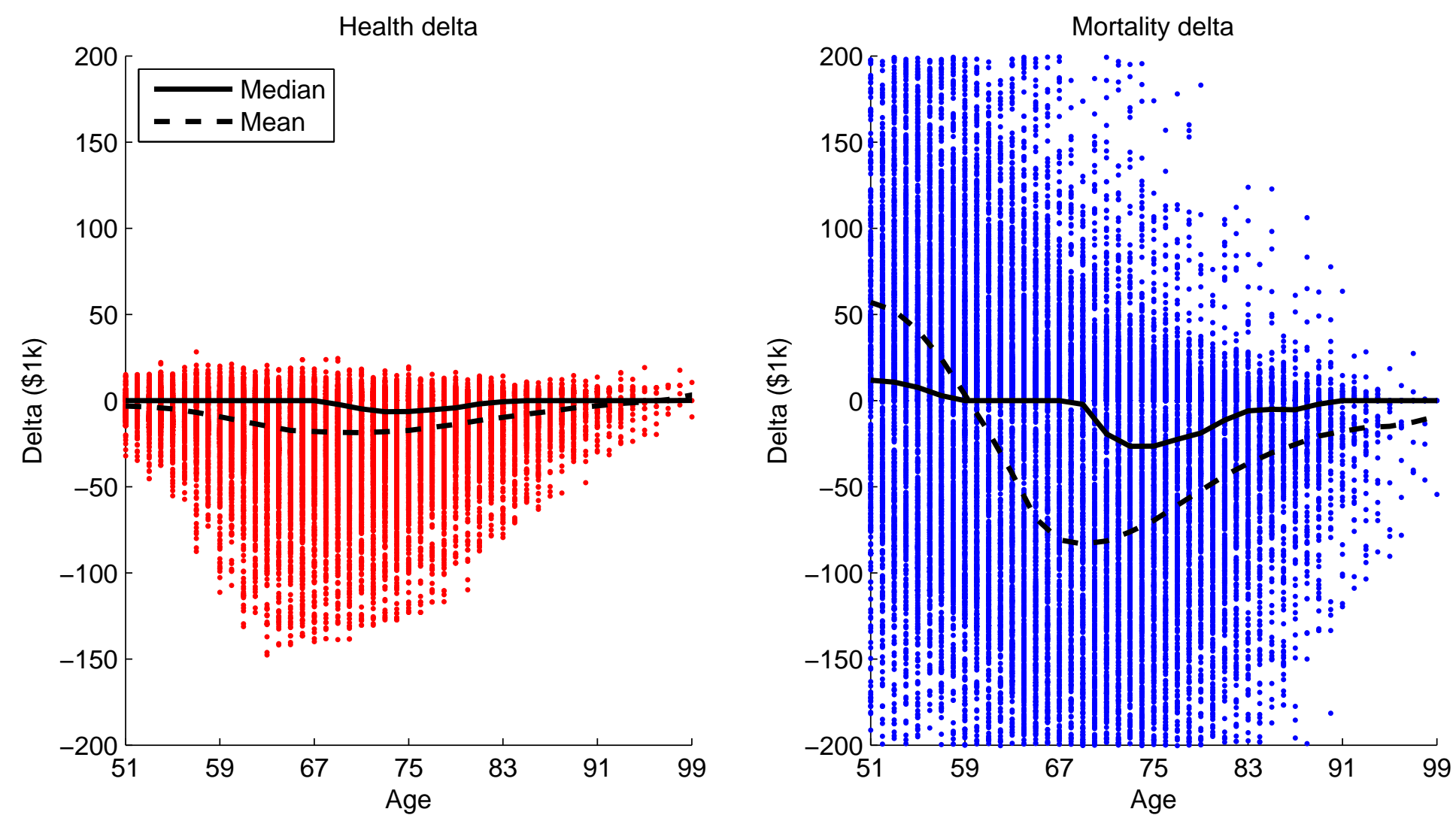

Figure 4: Health and Mortality Delta Implied by Household Insurance Choice

The left (right) panel reports the median and mean health (mortality) delta by age, smoothed around a plus and minus two-year window. Each dot represents one of 32,778 household-interview observations in the Health and Retirement Study for the period 1992 to 2006. 

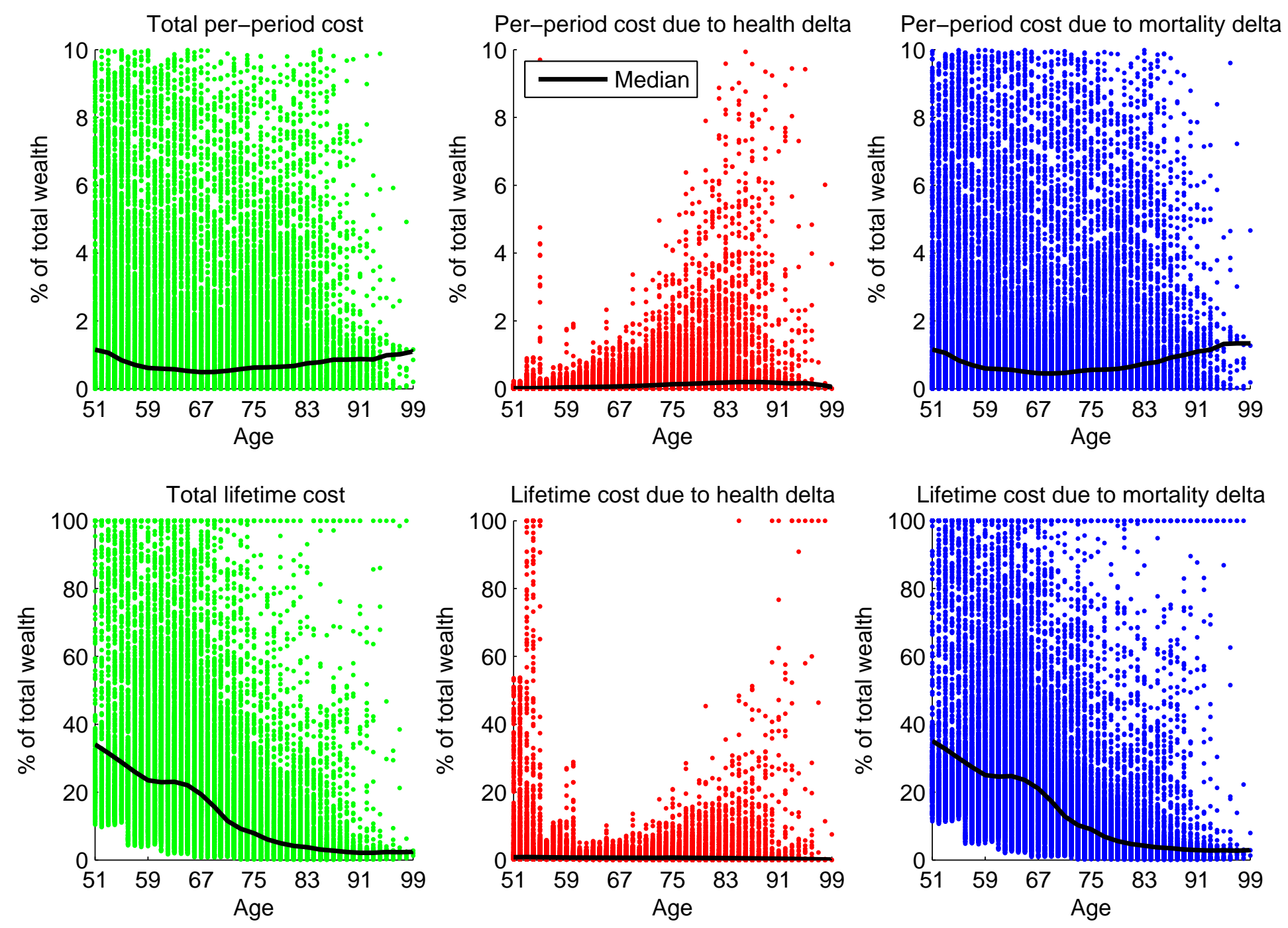

Figure 5: Welfare Cost of Household Insurance Choice

This figure reports the median welfare cost by age, smoothed around a plus and minus two-year window and expressed as a percentage of total wealth. The welfare cost for each household is measured by the deviations of the observed health and mortality delta from the optimal health and mortality delta. The lifetime cost is based on the probability of future ownership of health and longevity products, implied by the probit model in Table 8. Each dot represents one of 32,778 household-interview observations in the Health and Retirement Study for the period 1992 to 2006. 

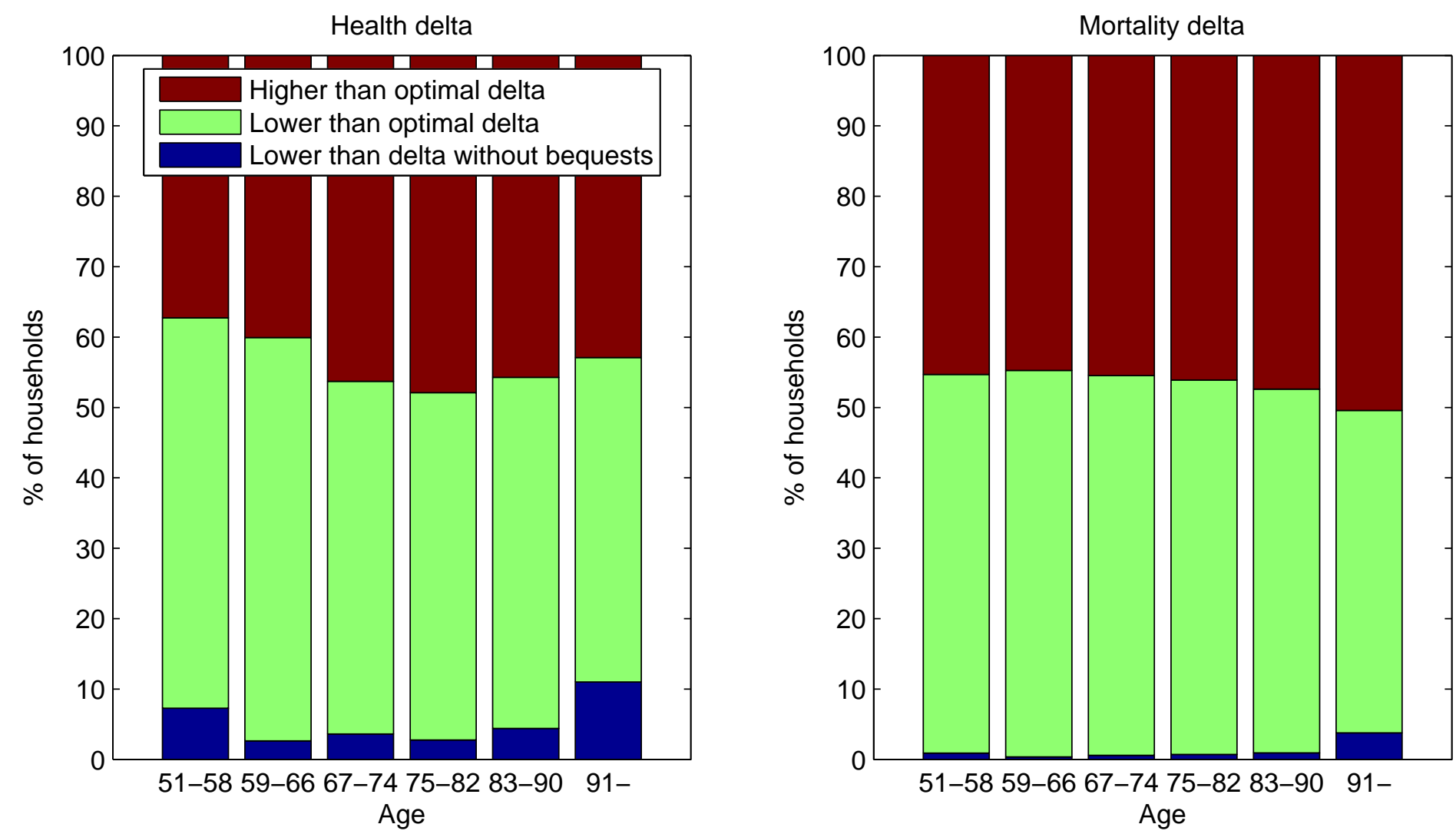

Figure 6: Deviations of the Observed Health and Mortality Delta from the Optimal Health and Mortality Delta The left (right) panel reports the percentage of households whose health (mortality) delta is higher than the optimal health (mortality) delta, whose health (mortality) delta is lower than the optimal health (mortality) delta, and whose health (mortality) delta is lower than that implied by a life-cycle model without a bequest motive. The optimal health and mortality delta are based on the preference parameters in Table 6. The sample consists of male respondents aged 51 and older in the Health and Retirement Study for the period 1992 to 2006. 

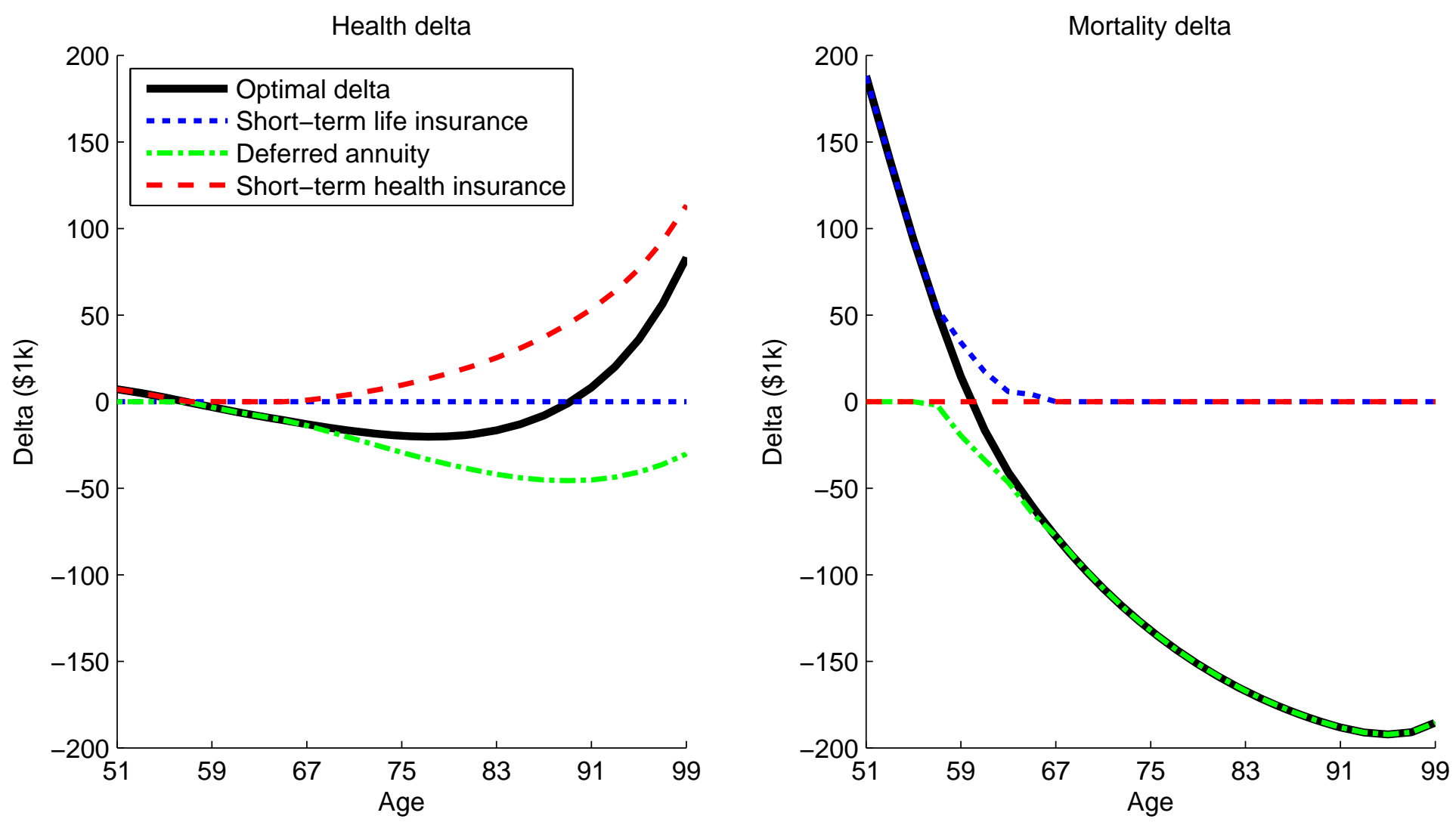

Figure 7: Optimal Health and Mortality Delta over the Life Cycle

The sum of health (mortality) delta for short-term life insurance, deferred annuities, and short-term health insurance equals the optimal health (mortality) delta at each age. Short-term policies have maturity of two years, and the income payments from deferred annuities start at age 65. The reported estimates are for male respondents in good health at age 51, born 1936 to 1940 in the Health and Retirement Study. 